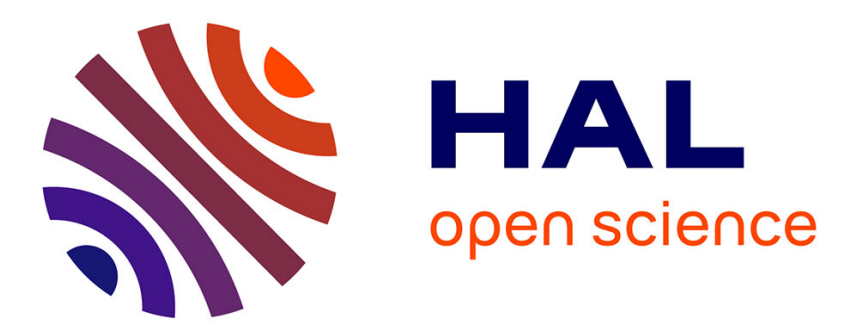

\title{
Lags in phenological acclimation of mountain grasslands after recent warming
}

Billur Bektaş, Wilfried Thuiller, Amelie Saillard, Philippe Choler, Julien Renaud, Marie-pascale Colace, Raphael Della Vedova, Tamara Münkemüller

\section{- To cite this version:}

Billur Bektaş, Wilfried Thuiller, Amelie Saillard, Philippe Choler, Julien Renaud, et al.. Lags in phenological acclimation of mountain grasslands after recent warming. Journal of Ecology, 2021, 109 (9), pp.3396 - 3410. 10.1111/1365-2745.13727 . hal-03419639

\section{HAL Id: hal-03419639 \\ https://hal.science/hal-03419639}

Submitted on 16 Nov 2021

HAL is a multi-disciplinary open access archive for the deposit and dissemination of scientific research documents, whether they are published or not. The documents may come from teaching and research institutions in France or abroad, or from public or private research centers.
L'archive ouverte pluridisciplinaire HAL, est destinée au dépôt et à la diffusion de documents scientifiques de niveau recherche, publiés ou non, émanant des établissements d'enseignement et de recherche français ou étrangers, des laboratoires publics ou privés. 


\section{Journal of Ecology}

\section{Lags in phenological acclimation of mountain grasslands after recent warming}

\begin{tabular}{|c|c|}
\hline Journal: & Journal of Ecology \\
\hline Manuscript ID & JEcol-2021-0154.R1 \\
\hline Manuscript Type: & Research Article \\
\hline $\begin{array}{r}\text { Date Submitted by the } \\
\text { Author: }\end{array}$ & $n / a$ \\
\hline Complete List of Authors: & $\begin{array}{l}\text { Bektaş, Billur; Université Grenoble Alpes, Université Savoie Mont Blanc, } \\
\text { CNRS, LECA } \\
\text { Thuiller, Wilfried; Université Grenoble Alpes, Université Savoie Mont } \\
\text { Blanc, CNRS, LECA } \\
\text { Saillard, Amélie; Université Grenoble Alpes, Université Savoie Mont } \\
\text { Blanc, CNRS, LECA } \\
\text { Choler, Philippe; Université Grenoble Alpes, Université Savoie Mont } \\
\text { Blanc, CNRS, LECA } \\
\text { Renaud, Julien; Université Grenoble Alpes, Université Savoie Mont Blanc, } \\
\text { CNRS, LECA } \\
\text { Colace, Marie-Pascale; Université Grenoble Alpes, Université Savoie Mont } \\
\text { Blanc, CNRS, LECA } \\
\text { Della Vedova, Raphael; Université Grenoble Alpes, CNRS, SAJF } \\
\text { Münkemüller, Tamara; Université Grenoble Alpes, Université Savoie Mont } \\
\text { Blanc, CNRS, LECA, }\end{array}$ \\
\hline Key-words: & $\begin{array}{l}\text { phenology, reciprocal transplant, warming experiment, transient } \\
\text { dynamics, mountain grasslands, NDVI, global change ecology, climate } \\
\text { change }\end{array}$ \\
\hline
\end{tabular}

\section{SCHOLARONE" Manuscripts}




\section{Introduction}

2 Climate warming is altering the biodiversity and functioning of mountain grasslands. Plant

3 communities will not immediately restructure to adjust to new air and soil temperatures and

4 associated changes in growing season length and snow cover (Carlson et al., 2017; Choler,

5 2015; Gobiet et al., 2014) but will show a number of transient responses (Hastings et al., 2018)

6 that are susceptible to lag behind climate warming (Alexander et al., 2018). Plastic responses of

7 plant phenotypes are prone to be triggered before species' abundance distributions and, finally,

8 community composition change (Nicotra et al., 2010). By monitoring these transient dynamics,

9 we can identify the short-term acclimation lags, i.e. the difference between the current state to

10 the one completely accustomed to a new climate, that can temporarily impair ecosystem

11 functions and services and can serve as early-warning signals of long-term degredations.

12 Quantifying and characterizing acclimation lags in addition to the responses to warming is

13 pivotal to understand how strongly adjusting plant species and communities are still

14 underperforming in comparison to well-adapted ones, how prone they are to be replaced and

15 outcompeted by better adapted ones, and how strongly ecosystem processes are impaired (Ryo

16 et al., 2019; Ström et al., 2011)

18 Among plastic responses to warming, plant phenology is one of the first to be triggered (Bellard

19 et al., 2012; Parmesan \& Hanley, 2015; Shen et al., 2015). Phenology refers to the timing and

20 duration of events in species' plant growth and reproduction over the year including budburst,

21 flowering, seed production and browning. Phenology strongly affects demographic performance,

22 community assembly and functions (Ackerly et al., 2000; Richardson et al., 2013). As climate

23 warming does not only result in higher mean temperatures but also in changed snow cover 
24 regimes and earlier starts and longer durations of growing seasons, it will affect different

25 aspects of plant phenology in different periods of the season. In the short-term, phenology can

26 allow acclimation of plant communities, notably for their main functions such as productivity

27 (Carlson et al., 2017; Piao et al., 2019). However, many questions on the transient responses

28 of mountain plant phenology to warming remain open: Do early or late season phenological

29 stages acclimate the fastest? How much time does it require to close acclimation lags? Are

30 species plastic in their responses or does acclimation require a restructuring of community

31 composition? It will depend on the answers to these questions which species and ecosystem

32 functions can prevail under climate warming. Therefore, we need to effectively measure

33 phenological responses to realistic warming scenarios and use informative phenological

34 indicators and ways to characterize acclimation lags.

36 Plant phenology and its response to warming climate is a globally long-studied phenomenon

37 with different experimental methods and at different organism levels (Piao et al., 2019; Winkler

38 et al., 2019; Wolkovich et al., 2012). For mountain grasslands, experimental warming showed

39 an advancement in greening, flowering and fruiting but a delayed browning at community-level

40 (Meng et al., 2019). However, even so community-level phenological responses often resemble

41 species-specific responses to warming (Diez et al., 2012), species with different characteristics

42 still show idiosyncratic responses (Arft et al., 1999; Dunne et al., 2003; Li et al., 2016; Smith et

43 al., 2012; S. P. Wang et al., 2014). Yet, it has been suggested that responses can potentially be

44 generalized at the growth form-level (Arft et al., 1999; Dunne et al., 2003; Oberbauer et al.,

45 2013). For example, graminoids and forbs are prone to give different responses as they differ in

46 functional and reproductive strategies (Reich et al., 2003; Shen et al., 2015; Siebenkäs et al.,

47 2015). 
49 Both at community level and at species level, a plethora of indicators have been suggested to

50 track changes in phenology for different periods in the season and to approximate different

51 demographic processes (Table 1). Consequently these indicators can respond differently to

52 warming. Therefore, a comprehensive study of warming effects and acclimation lags requires

53 not only to combine species and community level measures but also to integrate different

54 indicators to have the most complete overview on phenological changes. Here, we refer to

55 indicators that capture the start, end or pace of phenological stages as proxies for the timing of

56 plant growth and reproduction (Time-related indicators, Table 1) and we refer to indicators that

57 capture the length of phenophases (e.g. length of greening or flowering) and the number of

58 individuals passing to a certain phenophase as proxies of demographic performance

59 (Performance-related indicators, Table 1).

60

61 For time-related indicators, warming generally leads to an earlier and quicker onset of

62 phenophases in early-season while late-season responses are much more variable (Parmesan

63 \& Hanley, 2015). We are not aware of acclimation lag studies but expect faster acclimation to

64 warming in the early season as it has been shown that plants are plastic in adjusting the leaf-out

65 to changes in snow cover dynamics (Choler, 2015; Körner, 1999). In contrast, high mountain

66 grassland plants are adapted to short growing seasons and we expect that adjusting to longer

67 season lengths may be more difficult than to start the season earlier. For performance-related

68 indicators, warming leads to more plant growth but also more idiosyncratic species-specific

69 responses, e.g. to either decreases or increases in reproductive performance (Aldridge et al.,

70 2011; Carlson et al., 2017; Liu et al., 2012; Li et al., 2016). Additionally, while climate warming

71 might generally improve conditions for plant growth, it often is associated with lower snow cover 
72 protection and more frequent exposure to freezing events due to early snowmelt which may limit

73 some species (Choler, 2015). In contrast to time-related indicators, we expect

74 performance-related indicators to be more limited by physiological constraints, to be less plastic

75 and thus, be much slower in adjusting (Baptist et al., 2010).

76

77 Hitherto, warming studies have mainly focussed on a single type of indicator (Aldridge et al.,

78 2011; Li et al., 2016; Meng et al., 2019; S. P. Wang et al., 2014; T. Wang et al., 2014) (but see

79 counter examples: (H. Wang et al., 2020; S. Wang et al., 2014). and quantified phenological

80 changes as a response to warming (i.e. the warming effect) (Piao et al., 2019; Shen et al., 2015;

81 Wolkovich et al., 2012) but rarely measured acclimation lags (Ryo et al., 2019). Measuring

82 acclimation lags is a challenge as it requires to identify the adjusted community state after

83 complete acclimation (Visser \& Both, 2005).

84

85 Here, we suggest a combination of a transplant experiment with a conceptual framework to

86 measure transient warming and cooling effects and acclimation lags in mountain grasslands

87 (Fig. 1). We added cooling effects to test for reciprocality and to find out whether the acclimation

88 to new thermal conditions in mountain grasslands is generally a slow phenomenon (Crous,

89 2019). Our reciprocal transplant experiment along an elevation gradient simulates three degrees

90 of warming and longer growing seasons hence, a realistic warming scenario for the Alps for this

91 century (see projections for RCP4.5 and 8.5 scenarios: Jacob et al., 2014; Vorkauf et al., 2021).

92 We transplanted alpine communities 500m downwards to subalpine conditions to simulate

93 climate warming (Fig. 1A, AlpineWarmed) and, reciprocally, we transplanted subalpine

94 communities 500m upwards (Fig. 1A, SubalpineCooled). We controlled for transplantation

95 effects at both sites with control plots (Fig. 1A, AlpineControl and SubalpineControl, resp.). We 
96 suggest measuring warming (or cooling) effects by comparing AlpineControl to AlpineWarmed 97 plots (or SubalpineControl to SubalpineCooled plots, Fig. 1C).

99 To measure acclimation lags we assume that plants in control plots are in equilibrium with 100 climatic conditions. To justify this assumption despite ongoing climate change, we argue that i) 101 the historical climate warming is a slow and long-term phenomenon compared to the 102 experimental manipulation and thus negligible in comparison (Appendix Table S3), and ii) the 103 ongoing climate change has not induced yet a trend of longer growing seasons even though this 104 is an expected phenomenon (Jacob et al., 2014; J. Wang et al., 2021). Moreover, results would 105 only be more extreme if we would have transplanted communities from long-term climate 106 equilibrium. Acclimation lags can then be measured by comparing where the state of

107 AlpineWarmed plots (or SubalpineCooled plots) is relative to the shortest trajectory of 108 acclimation which we define here as the shortest distance between states of AlpineControl and 109 Subalpine Control plots (Fig. 1B, D). We suggest two measurements (Fig. 1D): Acclimation lags 110 can be big either because little acclimation has been achieved yet and the still to cover distance 111 is much larger than the distance already covered (deficient acclimation) and/or because

112 transient adjustments deviate in direction from the shortest trajectory to complete acclimation 113 (deviating acclimation). Theoretically, we expect that in the very long-term lags will close and 114 compared plots will be indistinguishable.

115 Combining a species to community scale approach, a multi index approach for phenology and 116 our conceptual framework, we asked whether: i) mountain grassland phenology completely 117 acclimated in timing and performance over three years of warming; ii) the lag in acclimation was 118 due to deficient and/or divergent warming effects and iii) the transient responses to warming 119 and cooling were symmetric. 


\section{Methods}

121 Experimental Design

122 The experiment was implemented close to the Col du Lautaret $\left(45^{\circ} 02^{\prime} 04^{\prime \prime} \mathrm{N} 06^{\circ} 24^{\prime} 18^{\prime \prime} \mathrm{E}\right)$ in the

123 French Alps in September 2016 (Fig. 1.A). The transplantation sites are the subalpine site

124 "Lautaret" ( $\left.45^{\circ} 04^{\prime} 00^{\prime \prime} \mathrm{N} 06^{\circ} 41^{\prime} 90^{\prime \prime} \mathrm{E}\right)$ at $1920 \mathrm{~m}$ altitude and the alpine site "Galibier" $\left(45^{\circ} 05^{\prime} 44^{\prime \prime} \mathrm{N}\right.$

$\left.12506^{\circ} 40^{\prime} 06^{\prime \prime} \mathrm{E}\right)$ at $2450 \mathrm{~m}$ altitude. Sites are close to each other ( $2 \mathrm{~km}$ airline distance), have a

126 similar orientation (South-East at alpine and South-South-West at subalpine site), bedrock

127 (base-riched flysch) and soil (dystric cambisols). During the observation-period (autumn 2016 -

128 autumn 2019), average annual soil temperature at the subalpine site was $3.2^{\circ} \mathrm{C}$ warmer than at

129 the alpine site (and days with similar temperatures at the two sites were very rare), average July

130 soil temperature was $3.1^{\circ} \mathrm{C}$ warmer and snow free season was 58.7 days longer (Table S1, Fig.

131 2.A). At the subalpine site, plant communities were mainly dominated by the graminoids

132 Patzkea paniculata, Carex sempervirens, Festuca nigrescens and the forbs Centaurea uniflora,

133 Helianthemum nummularium, and Meum athamanticum (Appendix Fig. S13). At the alpine site,

134 plant communities were mainly dominated by the graminoids Carex sempervirens, Festuca

135 nigrescens, Poa alpina and the forbs Potentilla aurea, Trifolium alpinum, and Geum montanum

136 (Appendix Fig. S13). Overall, the dominant graminoid species in AlpineControl and

137 SubalpineControl plots makeup to $22.5 \%$ and $26.5 \%$ of relative abundance, respectively. All

138 plant communities were dominated by perennial species.

140 In 2016, to simulate the effect of warming on alpine grasslands, we transplanted 10 replicates

$1414 \mathrm{~m}^{2}$ blocks of vegetation with at least $20 \mathrm{~cm}$ of their intact belowground parts and the

142 surrounding soils from the alpine to the subalpine site (AlpineWarmed plots in the following). For 
143 transport, each block was cut in $4 \times 1 \mathrm{~m}^{2}$ subblocks that were re-assembled in their original 144 composition when re-planted. To simulate the effect of cooling on subalpine communities, 10 145 intact $4 \mathrm{~m}^{2}$ blocks of vegetation and soils were transplanted from the subalpine to the alpine site 146 (SubalpineCooled plots). To control for the transplantation stress, we also horizontally

147 transplanted 10 intact $1 \mathrm{~m}^{2}$ blocks at both the subalpine and the alpine sites (SubalpineControl 148 plots and AlpineControl plots, respectively). Around the turfs we placed water permeable root 149 barriers to avoid root ingrowth from the natural vegetation around the plots. At both sites, cattle 150 and sheep were kept out by electric fences.

\section{Defining the growing season}

152 We considered the start and end of phenological events always relative to the start of the 153 growing season and the end of growing season, respectively (Table S1). This choice assures

154 that i) plots in different sites and years are comparable and ii) we compare the direct

155 phenological response rather than the differences in calendar dates (Johansson et al., 2013).

156 We defined the start (end) of the growing season as the first date when the NDVI based on

157 MODIS (Moderate Resolution Imaging Spectroradiometer) remote-sensed data was above

158 (below) 0.1 and the locally measured daily soil temperature was above (below) $1^{\circ} \mathrm{C}$ (Choler,

159 2015, 2018) (Fig. 2). For the remote-sensing data (RS-based NDVI), we downloaded the

160 MOD09Q1 surface reflectance products corresponding to tile h18.v4 (40-50॰ N, 0-15.6॰ E) from

161 the Land Processes Distributed Active Archive Center (LP DAAC). We used surface reflectance

162 in the red and near-infrared to calculate the 250m-resolution NDVI 8-days times series

163 corresponding to the two sites. The RS-based NDVI time series data were BISE (Best Index

164 Slope Extraction) corrected, gap-filled with cubic spline interpolation and smoothed using the

165 Savitzky-Golay filter (Choler, 2015). For the local soil temperature measurements, we equipped 
166 the two sites with standalone soil temperature data loggers (Hobo pendant UA, Onset Computer

167 Corporation, Bourne, MA) buried at $5 \mathrm{~cm}$ below ground. We smoothed daily soil temperature

168 time series with cubic spline interpolation.

169 On site measurements and phenological indicators

\section{Community-level}

171 We tracked the phenology at community-level using NDVI as a measurement of greening and a

172 proxy for photosynthetic activity and plant growth (Myneni \& Williams, 1994) (Fig. 2.C). We

173 measured NDVI (Normalized Difference Vegetation Index) in each treatment subblock

174 (10 x $4 \times 1 \mathrm{~m}^{2}$ subblocks for AlpineWarmed and for SubalpineCooled) and in each control block

175 (10 x $1 \mathrm{~m}^{2}$ blocks for AlpineControl and SubalpineControl) with three measurement repetitions

176 once (twice at maximum growth) per week during the growing seasons of the years 2017, 2018

177 and 2019. We took the measurements with a Decagon ProCheck spectral reflectance sensor for

178 NDVI with $630 \mathrm{~nm}$ (red) and $800 \mathrm{~nm}$ (near-infrared) spectral irradiance. The measurements

179 were taken at clear sky from 11am to $2 \mathrm{pm}$ during the same day for both sites. We derived

180 indicators from the NDVI curves over the growing season independently for each year,

181 treatment subblocks, control blocks and replicates. We gap-filled the time series (i.e. the other

182 days of the week) using cubic smoothing spline interpolation and smoothed using

183 Savitzky-Golay filter (Choler, 2015).

184

185 Based on these time series, we calculated several indicators. These indicators were based on

186 the definition of seasons within the whole growing season: i) early-season as the period starting

187 from the onset of the growing season to the last day when the NDVI values were below the $90 \%$

188 of the maximum NDVI, ii) mid season as the period when the NDVI values stayed above $90 \%$ of 
189 the maximum NDVI, iii) late-season as the period between the first day where NDVI values 190 dropped below $90 \%$ of the maximum NDVI until the offset of the growing season. The threshold 191 choice (e.g. 80\% of the maximum NDVI) did not affect the results (unpublished). While the start

192 and end of growing seasons were identified with MODIS remote-sensed data, we got to capture 193 the unique phenological dynamics in plant growth of each plot repetition by i) starting NDVI 194 measurements right after the snow melt when the field site was accessible, ii) identifying the 195 maximum NDVI based on field measurements for each plot.

197 We calculated time-related indicators as (Table 1): i) the days from the start of growing season 198 until $90 \%$ of the maximum plant growth (greening days), ii) greening speed as the rate of 199 increase in the NDVI values (i.e. from 0.1 of onset value to $90 \%$ of maximum NDVI value) 200 during early-season (Eq.2), iii) ratio of mid-season days to growing season days, iv) days after 201 90\% of the maximum plant growth until the end of growing season (browning days), v) browning 202 speed as the rate of decrease in the NDVI values (from $90 \%$ of maximum NDVI value to 0.1 of 203 offset value) during late-season (Eq.3).

$$
\text { Greening speed }=\left|\frac{0.9 \times \text { maxNDVI-0.1 }}{\text { Greening days }}\right| \text { (eqn 1) }
$$

$$
\text { Browning speed }=\left|\frac{0.1-0.9 \times \operatorname{maxNDVI}}{\text { Browning days }}\right| \text { (eqn 2) }
$$

210 We calculated performance-related indicators as proxies for biomass production and plant 211 growth as the areas under NDVI curves for each season (Table 1): i) early plant growth, ii) 
212 mid-season plant growth, iii) late plant growth and iv) annual (i.e. whole growing season) plant

213 growth.

\section{Species-level}

215 We tracked the phenology of focal dominant species (Appendix Table S2) in one sub-block of

216 each treatment block $\left(20 \times 1 \mathrm{~m}^{2}\right.$ sub-blocks in total) and in each control block $\left(20 \times 1 \mathrm{~m}^{2}\right.$ blocks

217 in total) every week during the growing seasons of 2017,2018 and 2019 . The selected

218 dominant species for the blocks with subalpine origin (SubalpineControl and SubalpineCooled)

219 were Patzkea paniculata, Carex sempervirens, Festuca nigrescens, Centaurea uniflora,

220 Helianthemum nummularium, and Meum athamanticum. The selected species for the blocks

221 with alpine origin (AlpineWarmed and AlpineControl) were Carex sempervirens, Festuca

222 nigrescens, Poa alpina, Potentilla aurea, and Trifolium alpinum, Geum montanum. We focus

223 here on the flowering, fruiting and dissemination phases as they reflect both early- and

224 late-season plant growth and reproduction phenologies. For each treatment subblock and

225 control block and each species, we determined the phenophases of 10 randomly selected

226 individuals (or the maximum number of individuals available when less than 10, see Appendix

227 TableS2 for percentage of observations when less than 10 individuals were observed). During

228 the peak of the growing season, we increased the frequency of NDVI and phenology

229 measurements to two times a week.

230

231 To reduce observation bias, we determined the start of the phenophase for a species as the

232 average of i) the last date when no individuals of the given species in the given phenophase

233 were observed and ii) the first date when the individuals of the given species in the given

234 phenophase were observed (vice versa for the end of phenophase) (Li et al., 2016). In case this 
averaging is not possible for the fact that the start or end of a phenophase were exactly the start or the end of the observation period on the field, the latter dates were taken.

\section{7}

238 We calculated time-related indicators as the days from the start of the growing season until the 239 mean date of the phenophase (Table 1) (Moussus et al., 2010).

241 We calculated performance-related indicators as (Table 1): i) the maximum ratio of individuals in 242 the phenophase to the number of sampled individuals (maximum 10) and ii) length of the 243 phenophase as the number of days between the onset and the end of the phenophase. (Li et 244 al., 2016). We excluded the length of the dissemination period from our study as we could not 245 collect the data over the whole dissemination period.

\section{Statistical analyses}

247 For our sets of phenological indicators (community- vs. species-level and time vs. performance 248 related), we analyzed four different treatment effects (Fig. 1.C): i) a warming effect by comparing 249 AlpineWarmed to AlpineControl plots, ii) a cooling effect by comparing SubalpineCooled to 250 SubalpineControl plots, iii) an acclimation lag after warming by comparing SubalpineControl to 251 AlpineWarmed plots, and iv) an acclimation lag after cooling by comparing AlpineControl to 252 SubalpineCooled plots. We conducted all the statistical analyses on R (R Core Team, 2017). 253

254 First, we tested the different treatment effects for each phenology indicator independently using 255 linear mixed effects models (nlme R package). At the community-level, we took the median of 256 the measurement repetitions to avoid including measurement errors due to the handheld NDVI 257 sensor. We considered treatment (custom contrast setting of above-explained comparisons, Fig. 
258 1.C) and year as fixed effects and subplot identity nested in plot identity as random effect. At the 259 species-level, we accounted for treatment, year and functional group (forbs or graminoids) as 260 fixed effects and block and species identity as random effects. As we conducted multiple tests, 261 we adjusted the p-values with multivariate t-distribution adjustment within the emmeans 262 package in $\mathrm{R}$ (Lenth, 2016). Here, we discuss the common responses of forbs and graminoids, 263 and report the species-specific responses in the Appendix (Fig. S1).

265 Secondly, in order to summarize results for timing vs. performance related phenological 266 indicators, we performed six different Principal Component Analyses (PCA) for time-related vs. 267 performance-related indicators for communities, forbs and graminoids. We visualized the first 268 two components of each PCA in the Appendix (Figs S4-6). For further analyses we determined 269 the number of significant principal components (PC) with Horn's parallel analysis in the R 270 package paran (Dinno, 2018; Franklin et al., 1995) (Appendix Fig. S12). As a result, we retained 271 the first two PCs For community-level PCAs two PCs were necessary to well capture the 272 variation, for species-level PCAs one PC was sufficient. Then calculated i) the multidimensional 273 acclimation lag (here "multidimensional" refers to the multiple indicators and the one or two PC 274 axes describing their variation) as the percentage of the remaining acclimation relative to the 275 complete acclimation (Fig. 1.D), ii) the deviation from the shortest acclimation trajectory as the 276 angle between the shortest acclimation trajectory and the warming effect (Fig. 1.D) with the 277 shortest acclimation trajectory being the euclidean distance between AlpineControl and 278 SubalpineControl plots In the case of two significant PCs (i.e. community level), we calculated 279 the euclidean distances with the dist function within the stats package and the angles with the 280 Angle function within the LearnGeom package in R (Briz-Redón \& Serrano-Aroca, 2018). In the 
case of a single significant PC (i.e. species level), angles were set either to $0^{\circ}$ (i.e. on the

282 acclimation trajectory) or to $180^{\circ}$ (opposite direction of the acclimation trajectory).

\section{3}

284 For interpretation, we speak of "acclimation lag" or "deficient warming effect" if we found a

285 significant difference between SubalpineControl and AlpineWarmed or AlpineControl and

286 SubalpineCooled and of "complete acclimation" otherwise. We speak of a divergent warming or

287 cooling effect if the observed trajectory deviates from the shortest trajectory of complete

288 acclimation. Importantly, acclimation lags can be much higher than $100 \%$ when the distance to

289 the optimally adapted community is not narrowing down over time but is instead increasing

290 during the transient dynamics. This can either happen when the adjustment response goes in a

291 "wrong" direction or when the adjustment response goes in the "right" direction but then

292 overshoots largely. We consider that the acclimation lags in warming and cooling are

293 symmetrical when they have almost the same (i.e. maximum 10\% difference) multidimensional

294 acclimation lag.

\section{Results}

\section{Was phenology completely acclimated after three years of warming?}

297 In a first step, we summarized results for the six sets of indicators (Table 1, combinations of 298 community, forbs, gramminoids with time-related and performance-related) and depending on

299 whether at least one indicator per set showed a significant acclimation lag, we give further

300 details in upcoming sections.

301 After three years of warming, the phenology of communities and focal species did not

302 completely acclimate, with the exception of graminoids (Fig. 3). For time-related indicators (Fig.

303 3.A), we observed complete acclimation to warming in most cases, especially during 
304 early-season and flowering. However, late-season phenology (i.e. days after max plant growth)

305 for communities and fruiting phenophase for forbs showed a significant acclimation lag.

306 For performance-related indicators (Fig. 3.B), we observed significant acclimation lags under

307 warming except for the graminoids. Both annual and mid-season plant growth for communities

308 and flowering phenophase (i.e. both flowering length and max \% flowering) for forbs failed to

309 reach complete acclimation.

\section{Was the warming effect on phenology deficient and/or divergent?}

311 Both deficient and divergent warming effects were responsible for the observed acclimation lags

312 (Fig. 4). However, lag size and deviation angle were dependent on the focal organism level and

313 phenological indicators.

314

315 For time-related indicators, the community-level acclimation lag was relatively small, 10\%, and

316 deviated only slightly from the shortest trajectory, $5^{\circ}$ (Fig. 4). With warming and longer season

317 length (Figs 2 \& Table S1), alpine community plant growth in the early-season slowed down and

318 communities took longer to reach their maximum plant growth (compared to AlpineConrol). In

319 late-season, communities decreased browning speed and increased browning days (i.e. days

320 after max plant growth) but failed to acclimate to the complete use of the late-season which

321 constitutes the major part of the acclimation lag. Interestingly, plant communities could only

322 acclimate their greening speed to longer season length in the third year but failed to do so in the

323 first two years after transplantation (Appendix Fig. S6.A). At the species-level, forbs did not only

324 fail to close the acclimation lag due to the absence of any warming effect (Figs $3 A$, 4), but they

325 even increased the lag by responding in the "wrong" direction (i.e. $180^{\circ}$ away from the shortest 
326 trajectory to complete acclimation. Specifically, fruiting for the AlpineWarmed species started

327 earlier than for the SubalpineControls in all three years after the transplantation.

328

329 For performance-related indicators, the community-level acclimation lag was relatively large,

$33026 \%$, but deviated only moderately from the shortest trajectory, $15^{\circ}$ (Fig. 4). Thus, even if

331 communities could increase their performance during early- and late-season, their

332 underperformance in the most important mid-season resulted in an important acclimation lag

333 (Fig. 3). In addition, this acclimation lag tended to increase over years (Appendix Fig. S7.A).

334 Forbs showed an even bigger acclimation lag (685\%) because they responded in the "right"

335 direction but exceeded far beyond the acclimation state. Notably, such large lags occur because

336 the original distance between the phenology of alpine and subalpine plants was small and the

337 response is measured relative to this original distance (Fig. 4). This was especially the case for

338 reproduction in the indispensable flowering stage (length of flowering period and number of 339 individuals reaching this phenophase) (Fig. 3).

\section{Were acclimation lags in warming and cooling symmetric?}

341 Acclimation lags in warming and cooling were not always symmetric. However, the strongest

342 acclimation lags caused by warming (i.e. performance-related indicators for communities and

343 forbs and time-related indicators for forbs) were symmetric for cooling (Fig. 4, Appendix Figs S4

$344 \&$ S5).

345 For time-related indicators, cooling caused a larger acclimation lag and stronger deviation from

346 the shortest trajectory than warming at the community-level. Forbs were on the shortest

347 acclimation trajectory after cooling in contrast to their deviating response to warming response

348 but the sizes of acclimation lags were similar (Fig. 4). 
349 For performance-related indicators, at the community-level, acclimation lags and deviations

350 from shortest trajectories were comparable for warming and cooling (Fig. 4 \& Appendix Fig.

351 S5.A). After cooling, annual and mid-season plant-growth could acclimate completely but early-

352 and late-season plant growth failed to acclimate (Appendix Fig. S3.B). Forbs suffered even

353 more from cooling than from warming and this was true for lag size and deviation from shortest

354 trajectories. This trend holds for graminoids even though their acclimation lags were not

355 significant.

\section{Discussion}

357 The phenology of mountain grasslands is known to strongly respond to climate change but so

358 far little was known about remaining acclimation lags. Here, we built on our conceptual

359 framework and a reciprocal transplant experiment to unravel whether phenological responses to

360 warming and cooling follow the shortest trajectories to complete acclimation and how big

361 remaining lags to complete acclimation are. We found that important aspects of phenology did

362 not acclimate after three years of warming. This suggests that the projected climate warming is

363 exceeding the limits of phenological plasticity of the here studied grasslands. This was

364 especially true for indicators that are key for demographic performance and thus success. Forbs

365 and overall community phenology were most affected, while graminoids coped overall well with

366 climate changes. Importantly, even though we observed strong warming effects, they were not

367 strong enough to lead to complete acclimation and we also found that transient dynamics

368 largely deviated from the shortest trajectory to acclimation, especially for forbs. Finally, the

369 symmetry between acclimation lags under warming and cooling underlines that important

370 phenological processes adjust too slowly. This might indicate that the functioning of mountain

371 grasslands under the threat of climate change can be reversible in the short-term. 


\section{Timing of phenological events}

373 Earlier works found that climate warming led to earlier phenology (experimental warming: Meng 374 et al., 2018, 2019; review on existing studies: Parmesan \& Hanley, 2015; review on alpine 375 ecosystem: Winkler et al., 2019) and faster plant growth (H. Wang et al., 2020). In apparent 376 contradiction, our climate warming experiment promoted later phenology (i.e. later maximal 377 plant growth, later starts of fruiting and dissemination periods of graminoids) and slower 378 early-season increase of growth (i.e. slower greening speed). These warming effects allowed 379 complete acclimation of the early- and mid-season timing of phenology to subalpine conditions 380 for graminoids and communities. One major reason for this difference with other studies is that 381 we used the growing season start and not calendar days as a reference (Johansson et al., 382 2013). Our main arguments for this choice are that the snow-free growing season is a major 383 driver of alpine ecosystems (Choler 2015), that plants physiologically respond to the first frost 384 free days and that thus the comparison among study sites is ecologically less meaningful when 385 it is based on calendar days. Another reason for our results is that with our in situ transplant 386 experiment, we did not only manipulate temperature but also the expected accompanying 387 changes in snow cover and growing season length (Choler 2015). In fact, once we calculated 388 the warming effect on greening days based on calendar days, we found an advancement too 389 (i.e. 24.85, with $\mathrm{p}<.001$ according to two sample t-test) but this reflects mainly the 390 advancement of snow melt.

392 Our results are consistent with apparent strategies of alpine communities: alpine conditions 393 force plants to squeeze life cycles in shorter growing seasons (Körner, 1999) and induce faster 394 plant growth right after the snow melt that is later in the year and thus, plants experience higher 
395 air temperatures directly after the snowmelt (Jonas et al., 2008). Yet, with warming and longer 396 growing seasons (just as in subalpine conditions), snowmelt is earlier, the protective effect of 397 snow cover is lost and thus, lower air temperatures are accompanied by potential spring 398 freezing events that together slow down plant growth in the early-season and can kill flower 399 buds and leaves of frost-sensitive species (Choler, 2018; D. Inouye, 2000; D. W. Inouye, 2008). 400 For the end of the growing season, we found in concordance with $\mathrm{H}$. Wang et al. (2020) that 401 plant communities could not sustain the high mid-season plant growth rates. Potential 402 explanations are warming-associated increases of drought stress (H. Wang et al., 2020) (i.e. 403 even though the air-borne estimated water balance of precipitation and evapotranspiration is 404 comparable between sites, unpublished results) or inherent allocation trade-offs (Johansson et 405 al., 2013).

407 In sum, alpine plant communities adjusted well to warmer conditions and higher uncertainties at 408 the beginning of the growing season but could not fully achieve their adaptation to faster cycles 409 at the end of the growing season.

\section{Phenological indicators linked to performance}

411 In our experiment, the warming of grasslands increased yearly plant community growth (i.e. 412 photosynthetic activity approximated by NDVI curves) which is consistent with several earlier 413 studies (Cao et al., 2015; Carlson et al., 2017; S. Wang et al., 2012; Yang et al., 2019) but in 414 contradiction to $\mathrm{H}$. Wang et al. (2020). Our observed yearly increase was due to increased early 415 and late plant growth, despite reduced mid-season plant growth. While our early-season results 416 coincide with those of $\mathrm{H}$. Wang et al. (2020), they differ for the mid and late-season (i.e. no 417 change and decrease). Reasons might be the fact that they i) could only record for $2^{\circ} \mathrm{C}$ of 
418 warming and ii) defined early- and late-seasons on the basis of months rather than considering 419 yearly differences in seasonal dynamics (i.e. interannual differences in start and end of growing 420 season). Here, we suggest that i) when $3^{\circ} \mathrm{C}$ is exceeded, a negative warming effect can be 421 imposed on mid-season community performance and ii) it is important to consider interannual 422 differences in identifying the seasons and warming effects on them.

424 Interestingly, in our experiment these strong warming effects were mostly due to short-term 425 responses of the communities, such as phenotypic plasticity, and not due to compositional 426 changes of plant communities. As most species in our observed grasslands were perennials, 427 limited species turnover took place in the first three years after transplantation (Appendix Fig. 428 S8).

430 Going a step further than merely describing the warming effect, we also showed that the 431 significant increase of growth was not sufficient to close the acclimation lag completely. In other 432 words, better-adapted grassland species originating from the subalpine area take better 433 advantage of the more favorable climate and grow better over the year. In line with these 434 results, it has already been shown that a positive demographic response to warming is not 435 always able to prevent extinction (Sheth \& Angert, 2018). The reason for the remaining 436 acclimation lag is probably functional traits of subalpine communities (e.g. height, Specific leaf 437 area) being better adapted to the favorable climate than those of alpine communities.

439 The community-wide warming effects on growth do not necessarily translate into increased 440 reproductive performance at the species-level (Doak \& Morris, 2010). Earlier studies found 441 idiosyncratic warming effects on reproductive performance at the species-level. Some found an 
442 increase (Iler et al., 2019; Kudernatsch et al., 2008; Li et al., 2016), no change at all (Dorji et al., 443 2020) or a decrease (Aldridge et al., 2011; Gugger et al., 2015; Liu et al., 2012) depending on 444 species and ecosystem and others identified species-specific responses (S. Wang et al., 2014; 445 Winkler et al., 2019). In our study, we could relate the species-specific responses to growth 446 forms with forbs failing to acclimate to warmer conditions (i.e. shorter flowering period, fewer 447 individuals flowering) but alpine graminoids performing as well as subalpine graminoids under 448 warmer, subalpine climate. This is in line with independent Ellenberg indicator values (i.e. 449 categorical values indicating the species' abiotic niche; (Bartelheimer \& Poschlod, 2016) 450 suggesting that the dominant forbs in our study system are much less tolerant to variation in 451 temperature (and moisture) than the dominant graminoids (Appendix Fig. S9). Specifically, we 452 argue that problems of forbs to acclimate could be linked to: i) disrupted vernalization (i.e. flower 453 bud formation depends on low temperatures, especially during winter; (Liu et al., 2012), ii) more 454 allocation of resources to somatic growth than to reproduction (Johansson et al., 2013; Liu et 455 al., 2012), iii) shading created by graminoids that have the potential to grow taller than forbs. 456

457 The observed acclimation lag of forbs in flowering performance is prone to cascade to the other 458 trophic levels, specifically to associated pollinators (Gezon et al., 2016) and thus to further 459 disrupt functioning of warmed alpine communities. In addition, responses specific to growth form 460 may also cause a community composition shift in favor of graminoids. This is in line with a 461 recent global review on the ecological flexibility of gramminoids in their climate and habitat 462 range, their success in establishment and dispersal and ecological competitiveness due to their 463 functional and physiological traits (Linder et al., 2018). Yet, such shift in communities also risks 464 the well-being of the whole multitrophic network and ecosystem functioning through further 465 reduction of pollination services (Burkle et al., 2013; Gezon et al., 2016). In our study site, we 
already found indications of a significant acclimation lag on pollinator diversity after three years of warming (Appendix Fig. S10).

468

469 The short-term community-level and growth form-specific results point to expected long-term

470 responses of mountain grasslands (Pironon et al., 2017), including range shifts and

471 restructuring of communities. With warming, we know that some plant communities will be able

472 to track their climatic niche and some will not, either due to migration failures or absence of

473 niche space on mountain tops (Alexander et al., 2015, 2016; Matteodo et al., 2013). In a

474 scenario where subalpine plant communities can track their climate but alpine communities

475 remain within their current niche, alpine species may not be able to increase their demographic

476 performance either in plant growth or in reproduction fast enough and will thus be outcompeted

477 by the subalpine species (Alexander et al., 2015, 2016). The increase in community plant

478 growth and the competitive exclusion of slower-growing alpine species will also change

479 plant-soil feedbacks. According to the "fast-slow" plant economics spectrum, faster growth is

480 associated to more exploitative plant traits (and thus, functional strategies), especially under

481 favorable environmental conditions (Martinez-Almoyna et al., 2020; Reich, 2014). Such an

482 aboveground functional strategy shift towards the faster part of the economic spectrum will

483 affect the microorganisms involved in plant litter composition (e.g. higher bacteria:fungi ratio),

484 will change their ecosystem functions (e.g. faster nutrient cycling) and will then feedback to the

485 plant communities, potentially further accelerating changes (Bardgett \& Wardle, 2010).

\section{Divergent warming effects}

487 It has been recently highlighted that perturbations to an ecosystem's steady state can trigger 488 transient responses of ecological relevance (Mari et al., 2017). The question is not only how long it 
489 will take until the new steady state is reached but also how strongly responses are initially amplified 490 before decaying towards a final state. Here we demonstrate that warming effects, especially on the 491 phenology of alpine forbs, can be not only divergent (Ryo et al., 2019) but can lead phenology far 492 away from any acclimation. In line with a previous long-term study (Wu et al., 2012), we found a 493 similar but weaker response at the community-level. Overall, determining the divergent 494 responses can inform us on the long-term trajectory of the warming effect, and can serve as an 495 early warning signal for negative impacts on ecosystem functioning (Scheffer et al., 2009). For 496 example, fine scale NDVI measurements on communities are relatively easy to implement and 497 according to our results, monitoring only for community productivity can serve for early detecting 498 shifts in communities and ecosystem functioning.

\section{Symmetry between acclimation lag after warming and cooling}

500 We found most of the acclimation lags after warming and cooling to be symmetric, indicating 501 some plasticity in phenological responses to climate change that is however not sufficient for

502 short-term acclimation to realistic warming scenarios. We conclude that slow phenological

503 acclimation to new thermal conditions is a general phenomenon for mountain plant

504 communities. Notably, for some phenological indicators (i.e. timing of community growth and

505 flowering performance of forbs), the acclimation lag after cooling was significantly wider than for

506 warming. It has been suggested earlier that for mountain grasslands, physiological limits at the

507 cold thermal range edge are much more pronounced than at the warm edge (Pellissier et al.,

508 2013). In addition, it has been shown that a major driver of the warm edge is competition

509 (Alexander et al., 2015), which has not yet started to act at its full force in our experiment.

510 However, decrease in flowering performance both with warming and cooling indicate that

511 flowering phenology is highly sensitive at both ends of the thermal limits (Li et al., 2016; S. P.

512 Wang et al., 2014). 
514 The question of symmetry might also have practical implications. With the advancing research

515 on climate warming, the reversibility of the warming effect at many levels is still an open debate

516 (Scheffer et al., 2001). The symmetric response between acclimation lag after warming and

517 cooling can also inform us on the reversibility of the impacts of warming. Here, it seems like

518 most of the warming impacts especially on aboveground productivity and flowering performance

519 can be reversible in the short-term. However, we also acknowledge that these observed

520 transient responses might be buffered by the ones at different levels or can even lead to other

521 cascading effects or critical transitions.

522

\section{Conclusion and perspectives}

524 With our reciprocal transplant experiment on mountain grasslands, we revealed that community

525 and species-level phenological responses to climate warming were not enough for their

526 complete acclimation to their new conditions in the short-term, except for graminoids. These

527 phenological acclimation lags probably impair other ecosystem functions, such as pollination

528 and plant-soil feedbacks. Short-term acclimation lags, and especially strong deviations from

529 acclimation trajectories, may also hint at long-term impairment of ecosystem functions and

530 restructuring of communities. This emphasizes the importance of characterizing the size and

531 direction of acclimation lags in upcoming global change research.

532

533 BB, WT and TM conceived the ideas and designed methodology; PC substantially helped with the

534 interpretation of the results and design of the conceptual framework; AS and TM organized the fieldwork;

535 MPC, JR, AS and TM established the protocol; JR managed the database; BB, RDV, JR and MPC 
collected the data; BB analysed the data; BB, WT and TM led the writing of the manuscript. All authors

537 contributed critically to the drafts and gave final approval for publication.

538

\section{Acknowledgements}

540 This research was funded by the DIPEE/FREE-Alpes federation, the

541 French Agence Nationale de la Recherche (ANR) through the TransAlp project

542 (ANR-20-CE02-0021) and the Lautaret Garden-UMS 3370 (Univ. Grenoble Alpes, CNRS, SAJF,

54338000 Grenoble, France), a member of the Zone Atelier Alpes and eLTER network and of

544 AnaEE-France (ANR-11- INBS-0001AnaEE-Services, Investissements d'Avenir frame). This

545 research was conducted within the Long-Term Socio-Ecological Research (LTSER) platform

546 Lautaret-Oisans, a site of the European Research Infrastructure eLTER. This study would not

547 have been possible without the help of Melodie Bourreau, Matthieu Fleuet and many other

548 interns and colleagues during the field and laboratory work.

550 References

Ackerly, D. D., Dudley, S. A., Sultan, S. E., Schmitt, J., Coleman, J. S., Randall Linder, C., Sandquist, D. R., Geber, M. A., Evans, A. S., Dawson, T. E., \& Lechowicz, M. J. (2000). The evolution of plant ecophysiological traits: recent advances and future directions. BioScience, 50(11), 979. https://doi.org/10.1641/0006-3568(2000)050[0979:teopet]2.0.co;2

Aldridge, G., Inouye, D. W., Forrest, J. R. K., Barr, W. A., \& Miller-Rushing, A. J. (2011). Emergence of a mid-season period of low floral resources in a montane meadow ecosystem associated with climate change. Journal of Ecology, 99(4), 905-913. https://doi.org/10.1111/j.1365-2745.2011.01826.x

Alexander, J. M., Chalmandrier, L., Lenoir, J., Burgess, T. I., Essl, F., Haider, S., Kueffer, C., 

McDougall, K., Milbau, A., Nuñez, M. A., Pauchard, A., Rabitsch, W., Rew, L. J., Sanders, N. J., \& Pellissier, L. (2018). Lags in the response of mountain plant communities to climate

563 change. Global Change Biology, 24(2), 563-579. https://doi.org/10.1111/gcb.13976

Alexander, J. M., Diez, J. M., Hart, S. P., \& Levine, J. M. (2016). When climate reshuffles competitors: A call for experimental macroecology. Trends in Ecology \& Evolution, 31(11), 831-841. https://doi.org/10.1016/j.tree.2016.08.003

Alexander, J. M., Diez, J. M., \& Levine, J. M. (2015). Novel competitors shape species' responses to climate change. Nature, 525(7570), 515-518. https://doi.org/10.1038/nature14952

Arft, A. M., Walker, M. D., Gurevitch, J., Alatalo, J. M., Bret-Harte, M. S., Dale, M., Diemer, M., Gugerli, F., Henry, G. H. R., Jones, M. H., Hollister, R. D., Jonsdottir, I. S., Laine, K., Levesque, E., Marion, G. M., Molau, U., Molgaard, P., Nordenhall, U., Raszhivin, V., ... Wookey, P. A. (1999). Responses of tundra plants to experimental warming: meta-analysis of the International Tundra Experiment. Ecological Monographs, 69(4), 491. https://doi.org/10.2307/2657227

Baptist, F., Flahaut, C., Streb, P., \& Choler, P. (2010). No increase in alpine snowbed productivity in response to experimental lengthening of the growing season. Plant Biology, 12(5), 755-764. https://doi.org/10.1111/j.1438-8677.2009.00286.x

Bardgett, R. D., \& Wardle, D. A. (2010). Aboveground-belowground linkages: biotic Interactions, ecosystem processes, and global change. Oxford University Press.

Bartelheimer, M., \& Poschlod, P. (2016). Functional characterizations of Ellenberg indicator values - a review on ecophysiological determinants. Functional Ecology, 30, 506-516. https://doi.org/10.1111/1365-2435.12531

Bellard, C., Bertelsmeier, C., Leadley, P., Thuiller, W., \& Courchamp, F. (2012). Impacts of 
climate change on the future of biodiversity. Ecology Letters, 15(4), 365-377. https://doi.org/10.1111/j.1461-0248.2011.01736.x

586

587

588

589

590

591

592

593

594

595

596

597

598

599

600

601

602

603

604

605

606

607

Briz-Redón, Á., \& Serrano-Aroca, Á. (2018). Novel pedagogical tool for simultaneous learning of plane geometry and R programming. https://doi.org/10.3897/rio.4.e25485

Burkle, L. A., Marlin, J. C., \& Knight, T. M. (2013). Plant-pollinator interactions over 120 years: loss of species, co-occurrence, and function. Science, 339(6127), 1611-1615. https://doi.org/10.1126/science.1232728

Cao, H., Zhao, X., Wang, S., Zhao, L., Duan, J., Zhang, Z., Ge, S., \& Zhu, X. (2015). Grazing intensifies degradation of a Tibetan Plateau alpine meadow through plant-pest interaction. Ecology and Evolution, 5(12), 2478-2486. https://doi.org/10.1002/ece3.1537

Carlson, B. Z., Corona, M. C., Dentant, C., Bonet, R., Thuiller, W., \& Choler, P. (2017). Observed long-term greening of alpine vegetation-a case study in the French Alps. Environmental Research Letters, 12(11), 114006. https://doi.org/10.1088/1748-9326/aa84bd

Choler, P. (2015). Growth response of temperate mountain grasslands to inter-annual variations in snow cover duration. Biogeosciences, 12(12), 3885-3897. https://doi.org/10.5194/bg-12-3885-2015

Choler, P. (2018). Winter soil temperature dependence of alpine plant distribution: Implications for anticipating vegetation changes under a warming climate. Perspectives in Plant Ecology, Evolution and Systematics, 30, 6-15. https://doi.org/10.1016/j.ppees.2017.11.002

Diez, J. M., Ibáñez, I., Miller-Rushing, A. J., Mazer, S. J., Crimmins, T. M., Crimmins, M. A., Bertelsen, C. D., \& Inouye, D. W. (2012). Forecasting phenology: from species variability to community patterns. Ecology Letters, 15(6), 545-553.

https://doi.org/10.1111/j.1461-0248.2012.01765.x

Dinno, A. (2018). paran: Horn's Test of Principal Components/Factors (R package version 
Doak, D. F., \& Morris, W. F. (2010). Demographic compensation and tipping points in climate-induced range shifts. Nature, 467(7318), 959-962. https://doi.org/10.1038/nature09439

612 Dorji, T., Hopping, K. A., Meng, F., Wang, S., Jiang, L., \& Klein, J. A. (2020). Impacts of climate 613 change on flowering phenology and production in alpine plants: The importance of end of 614 flowering. Agriculture, Ecosystems \& Environment, 291, 106795.

615 https://doi.org/10.1016/j.agee.2019.106795

616 Dunne, J. A., Harte, J., \& Taylor, K. J. (2003). Subalpine meadow flowering phenology 617 responses to climate change: integrating experimental and gradient methods. Ecological 618 Monographs, 73(1), 69-86.

619 https://doi.org/10.1890/0012-9615(2003)073[0069:smfprt]2.0.co;2

620 Franklin, S. B., Gibson, D. J., Robertson, P. A., Pohlmann, J. T., \& Fralish, J. S. (1995). Parallel 621 Analysis: a method for determining significant principal components. Journal of Vegetation 622 Science, 6(1), 99-106. https://doi.org/10.2307/3236261

623 Gezon, Z. J., Inouye, D. W., \& Irwin, R. E. (2016). Phenological change in a spring ephemeral: 624 implications for pollination and plant reproduction. Global Change Biology, 22(5), 625 1779-1793. https://doi.org/10.1111/gcb.13209

626 Gobiet, A., Kotlarski, S., Beniston, M., Heinrich, G., Rajczak, J., \& Stoffel, M. (2014). 21st 627 century climate change in the European Alps-A review. Science of The Total Environment, 628 493, 1138-1151. https://doi.org/10.1016/j.scitotenv.2013.07.050

629 Gugger, S., Kesselring, H., Stöcklin, J., \& Hamann, E. (2015). Lower plasticity exhibited by high630 versus mid-elevation species in their phenological responses to manipulated temperature 631 and drought. Annals of Botany, 116(6), 953-962. https://doi.org/10.1093/aob/mcv155 
632 Hastings, A., Abbott, K. C., Cuddington, K., Francis, T., Gellner, G., Lai, Y.-C., Morozov, A.,

633 Petrovskii, S., Scranton, K., \& Zeeman, M. L. (2018). Transient phenomena in ecology.

634 Science, 361(6406). https://doi.org/10.1126/science.aat6412

635 Iler, A. M., Compagnoni, A., Inouye, D. W., Williams, J. L., CaraDonna, P. J., Anderson, A., \&

636 Miller, T. E. X. (2019). Reproductive losses due to climate change-induced earlier flowering

637 are not the primary threat to plant population viability in a perennial herb. Journal of

638 Ecology, 107(4), 1931-1943. https://doi.org/10.1111/1365-2745.13146

639 Inouye, D. (2000). The ecological and evolutionary significance of frost in the context of climate 640 change. Ecology Letters, 3(5), 457-463. https://doi.org/10.1046/j.1461-0248.2000.00165.x

641 Inouye, D. W. (2008). Effects of climate change on phenology, frost damage, and floral

642 abundance of montane wildflowers. Ecology, 89(2), 353-362.

643 https://doi.org/10.1890/06-2128.1

644 Jacob, D., Petersen, J., Eggert, B., Alias, A., Christensen, O. B., Bouwer, L. M., Braun, A.,

645 Colette, A., Déqué, M., Georgievski, G., Georgopoulou, E., Gobiet, A., Menut, L., Nikulin,

646 G., Haensler, A., Hempelmann, N., Jones, C., Keuler, K., Kovats, S., ... Yiou, P. (2014).

647 EURO-CORDEX: new high-resolution climate change projections for European impact

648 research. Regional Environmental Change, 14(2), 563-578.

649 https://doi.org/10.1007/s10113-013-0499-2

650 Johansson, J., Bolmgren, K., \& Jonzén, N. (2013). Climate change and the optimal flowering

651 time of annual plants in seasonal environments. Global Change Biology, 19(1), $197-207$.

652 https://doi.org/10.1111/gcb.12006

653 Jonas, T., Rixen, C., Sturm, M., \& Stoeckli, V. (2008). How alpine plant growth is linked to snow

654 cover and climate variability. Journal of Geophysical Research, 113(G3).

655 https://doi.org/10.1029/2007jg000680 
656 Körner, C. (1999). Alpine Plant Life. Springer Science \& Business Media.

657 https://doi.org/10.1007/978-3-642-98018-3

658 Kudernatsch, T., Fischer, A., Bernhardt-Römermann, M., \& Abs, C. (2008). Short-term effects of 659 temperature enhancement on growth and reproduction of alpine grassland species. Basic and Applied Ecology, 9(3), 263-274. https://doi.org/10.1016/j.baae.2007.02.005

Lenth, R. V. (2016). Least-Squares Means: TheRPackagelsmeans.

$$
\text { https://doi.org/10.18637/jss.v069.i01 }
$$

Linder, H. P., Lehmann, C. E. R., Archibald, S., Osborne, C. P., \& Richardson, D. M. (2018).

$$
\text { Global grass (Poaceae) success underpinned by traits facilitating colonization, persistence }
$$
and habitat transformation. Biological Reviews of the Cambridge Philosophical Society,

$$
\text { 93(2), 1125-1144. https://doi.org/10.1111/brv.12388 }
$$

Liu, Y., Mu, J., Niklas, K. J., Li, G., \& Sun, S. (2012). Global warming reduces plant reproductive output for temperate multi-inflorescence species on the Tibetan plateau. The New Phytologist, 195(2), 427-436. https://doi.org/10.1111/j.1469-8137.2012.04178.x

Li, X., Jiang, L., Meng, F., Wang, S., Niu, H., Iler, A. M., Duan, J., Zhang, Z., Luo, C., Cui, S., Zhang, L., Li, Y., Wang, Q., Zhou, Y., Bao, X., Dorji, T., Li, Y., Peñuelas, J., Du, M., ...

Wang, G. (2016). Responses of sequential and hierarchical phenological events to warming and cooling in alpine meadows. Nature Communications, 7, 12489. https://doi.org/10.1038/ncomms12489

Mari, L., Casagrandi, R., Rinaldo, A., \& Gatto, M. (2017). A generalized definition of reactivity for ecological systems and the problem of transient species dynamics. Methods in Ecology and Evolution, 8(11), 1574-1584. https://doi.org/10.1111/2041-210x.12805

Martinez-Almoyna, C., Piton, G., Abdulhak, S., Boulangeat, L., Choler, P., Delahaye, T., Dentant, C., Foulquier, A., Poulenard, J., Noble, V., Renaud, J., Rome, M., Saillard, A., 
Thuiller, W., Münkemüller, T., \& The ORCHAMP Consortium. (2020). Climate, soil resources and microbial activity shape the distributions of mountain plants based on their functional traits. Ecography, 43(10), 1550-1559. https://doi.org/10.1111/ecog.05269

Matteodo, M., Wipf, S., Stöckli, V., Rixen, C., \& Vittoz, P. (2013). Elevation gradient of successful plant traits for colonizing alpine summits under climate change. Environmental Research Letters, 8(2), 024043. https://doi.org/10.1088/1748-9326/8/2/024043

Meng, F., Suonan, J., Zhang, Z., Wang, S., Duan, J., Wang, Q., Li, B., Luo, C., Jiang, L., Zhang, L., Liu, P., Renzeng, W., Lv, W., Wang, Z., Tsechoe, D., \& Du, M. (2018). Nonlinear responses of temperature sensitivities of community phenophases to warming and cooling events are mirroring plant functional diversity. Agricultural and Forest Meteorology, 253-254, 31-37. https://doi.org/10.1016/j.agrformet.2018.01.034

Meng, F., Zhang, L., Niu, H., Suonan, J., Zhang, Z., Wang, Q., Li, B., Lv, W., Wang, S., Duan, J., 692 Liu, P., Renzeng, W., Jiang, L., Luo, C., Dorji, T., Wang, Z., \& Du, M. (2019). Divergent responses of community reproductive and vegetative phenology to warming and cooling: asymmetry versus symmetry. Frontiers in Plant Science, 10, 1310. https://doi.org/10.3389/fpls.2019.01310

Moussus, J.-P., Julliard, R., \& Jiguet, F. (2010). Featuring 10 phenological estimators using simulated data. Methods in Ecology and Evolution, 1(2), 140-150. https://doi.org/10.1111/j.2041-210x.2010.00020.x Sensing of Environment, 49(3), 200-211. https://doi.org/10.1016/0034-4257(94)90016-7

702 P., Purugganan, Richards, C. L., Valladares, F., \& van Kleunen, M. (2010). Plant phenotypic 703 plasticity in a changing climate. Trends in Plant Science, 15(12), 684-692. 

https://doi.org/10.1016/j.tplants.2010.09.008

705

706

707

708

709

710

711

712

Oberbauer, S. F., Elmendorf, S. C., Troxler, T. G., Hollister, R. D., Rocha, A. V., Bret-Harte, M. S., Dawes, M. A., Fosaa, A. M., Henry, G. H. R., Høye, T. T., Jarrad, F. C., Jónsdóttir, I. S., Klanderud, K., Klein, J. A., Molau, U., Rixen, C., Schmidt, N. M., Shaver, G. R., Slider, R. T., ... Welker, J. M. (2013). Phenological response of tundra plants to background climate variation tested using the International Tundra Experiment. Philosophical Transactions of the Royal Society of London. Series B, Biological Sciences, 368(1624), 20120481. https://doi.org/10.1098/rstb.2012.0481

Parmesan, C., \& Hanley, M. E. (2015). Plants and climate change: complexities and surprises. Annals of Botany, 116(6), 849-864. https://doi.org/10.1093/aob/mcv169

Pellissier, L., Bråthen, K. A., Vittoz, P., Yoccoz, N. G., Dubuis, A., Meier, E. S., Zimmermann, N. E., Randin, C. F., Thuiller, W., Garraud, L., Van Es, J., \& Guisan, A. (2013). Thermal niches are more conserved at cold than warm limits in arctic-alpine plant species. Global Ecology and Biogeography: A Journal of Macroecology, 22(8), 933-941. https://doi.org/10.1111/geb.12057

Piao, S., Liu, Q., Chen, A., Janssens, I. A., Fu, Y., Dai, J., Liu, L., Lian, X., Shen, M., \& Zhu, X. (2019). Plant phenology and global climate change: current progresses and challenges. Global Change Biology, 25(6), 1922-1940. https://doi.org/10.1111/gcb.14619

Pironon, S., Papuga, G., Villellas, J., Angert, A. L., García, M. B., \& Thompson, J. D. (2017). Geographic variation in genetic and demographic performance: new insights from an old biogeographical paradigm. Biological Reviews of the Cambridge Philosophical Society, 92(4), 1877-1909. https://doi.org/10.1111/brv.12313

R Core Team. (2017). R: A Language and Environment for Statistical Computing [R Foundation for Statistical Computing Vienna, Austria]. https://www.r-project.org/ 
728 Reich, P. B. (2014). The world-wide "fast-slow" plant economics spectrum: a traits manifesto.

729 Journal of Ecology, 102(2), 275-301. https://doi.org/10.1111/1365-2745.12211

730 Reich, P. B., Buschena, C., Tjoelker, M. G., Wrage, K., Knops, J., Tilman, D., \& Machado, J. L.

731 (2003). Variation in growth rate and ecophysiology among 34 grassland and savanna

732 species under contrasting N supply: a test of functional group differences. New Phytologist,

733 157(3), 617-631. https://doi.org/10.1046/j.1469-8137.2003.00703.x

734 Richardson, A. D., Keenan, T. F., Migliavacca, M., Ryu, Y., Sonnentag, O., \& Toomey, M. (2013).

735 Climate change, phenology, and phenological control of vegetation feedbacks to the climate

736 system. Agricultural and Forest Meteorology, 169, 156-173.

737 https://doi.org/10.1016/j.agrformet.2012.09.012

738 Ryo, M., Aguilar-Trigueros, C. A., Pinek, L., Muller, L. A. H., \& Rillig, M. C. (2019). Basic

739 principles of temporal dynamics. Trends in Ecology \& Evolution, 34(8), 723-733.

$740 \quad$ https://doi.org/10.1016/j.tree.2019.03.007

741 Scheffer, M., Bascompte, J., Brock, W. A., Brovkin, V., Carpenter, S. R., Dakos, V., Held, H., van

742 Nes, E. H., Rietkerk, M., \& Sugihara, G. (2009). Early-warning signals for critical transitions.

$743 \quad$ Nature, 461(7260), 53-59. https://doi.org/10.1038/nature08227

744 Scheffer, M., Carpenter, S., Foley, J. A., Folke, C., \& Walker, B. (2001). Catastrophic shifts in

745 ecosystems. Nature, 413(6856), 591-596. https://doi.org/10.1038/35098000

746 Shen, M., Piao, S., Dorji, T., Liu, Q., Cong, N., Chen, X., An, S., Wang, S., Wang, T., \& Zhang,

747 G. (2015). Plant phenological responses to climate change on the Tibetan Plateau:

748 research status and challenges. National Science Review, 2(4), 454-467.

749 https://doi.org/10.1093/nsr/nwv058

750 Sheth, S. N., \& Angert, A. L. (2018). Demographic compensation does not rescue populations at 751 a trailing range edge. PNAS. https://doi.org/10.1101/117606 
752 Siebenkäs, A., Schumacher, J., \& Roscher, C. (2015). Phenotypic plasticity to light and nutrient 753 availability alters functional trait ranking across eight perennial grassland species. $A o B$

$754 \quad$ Plants, 7. https://doi.org/10.1093/aobpla/plv029

755 Smith, J. G., Sconiers, W., Spasojevic, M. J., Ashton, I. W., \& Suding, K. N. (2012).

756 Phenological changes in alpine plants in response to increased snowpack, temperature, 757 and nitrogen. Arctic, Antarctic, and Alpine Research, 44(1), 135-142.

$758 \quad$ https://doi.org/10.1657/1938-4246-44.1.135

759

760

761

762

763

764

765

766

767

768

769

770

771

772

773

774

775 Wang, S., Duan, J., Xu, G., Wang, Y., Zhang, Z., Rui, Y., Luo, C., Xu, B., Zhu, X., Chang, X., 
Cui, X., Niu, H., Zhao, X., \& Wang, W. (2012). Effects of warming and grazing on soil N availability, species composition, and ANPP in an alpine meadow. Ecology, 93(11), 2365-2376. https://doi.org/10.1890/11-1408.1

779

780

781

782

783

784

785

786

787

788

789

790

791

792

793

794

795

796

797

798

799

Wang, S. P., Meng, F. D., Duan, J. C., Wang, Y. F., Cui, X. Y., Piao, S. L., Niu, H. S., Xu, G. P., Luo, C. Y., Zhang, Z. H., Zhu, X. X., Shen, M. G., Li, Y. N., Du, M. Y., Tang, Y. H., Zhao, X. Q., Ciais, P., Kimball, B., Peñuelas, J., ... Zhang, F. W. (2014). Asymmetric sensitivity of first flowering date to warming and cooling in alpine plants. Ecology, 95(12), 3387-3398. https://doi.org/10.1890/13-2235.1

Wang, S., Wang, C., Duan, J., Zhu, X., Xu, G., Luo, C., Zhang, Z., Meng, F., Li, Y., \& Du, M. (2014). Timing and duration of phenological sequences of alpine plants along an elevation gradient on the Tibetan plateau. Agricultural and Forest Meteorology, 189-190, 220-228. https://doi.org/10.1016/j.agrformet.2014.01.021

Wang, T., Ottlé, C., Peng, S., Janssens, I. A., Lin, X., Poulter, B., Yue, C., \& Ciais, P. (2014). The influence of local spring temperature variance on temperature sensitivity of spring phenology. Global Change Biology, 20(5), 1473-1480. https://doi.org/10.1111/gcb.12509

Winkler, D. E., Lubetkin, K. C., Carrell, A. A., Jabis, M. D., Yang, Y., \& Kueppers, L. M. (2019). Responses of alpine plant communities to climate warming. In J. E. Mohan (Ed.), Ecosystem consequences of soil warming (pp. 297-346). Academic Press. https://doi.org/10.1016/b978-0-12-813493-1.00013-2

Wolkovich, E. M., Cook, B. I., Allen, J. M., Crimmins, T. M., Betancourt, J. L., Travers, S. E., Pau, S., Regetz, J., Davies, T. J., Kraft, N. J. B., Ault, T. R., Bolmgren, K., Mazer, S. J., McCabe, G. J., McGill, B. J., Parmesan, C., Salamin, N., Schwartz, M. D., \& Cleland, E. E. (2012). Warming experiments underpredict plant phenological responses to climate change. Nature, 485(7399), 494-497. https://doi.org/10.1038/nature11014 
800 Wu, Z., Dijkstra, P., Koch, G. W., \& Hungate, B. A. (2012). Biogeochemical and ecological 801 feedbacks in grassland responses to warming. Nature Climate Change, 2(6), 458-461.

802 https://doi.org/10.1038/nclimate1486

803 Yang, J., Dong, J., Xiao, X., Dai, J., Wu, C., Xia, J., Zhao, G., Zhao, M., Li, Z., Zhang, Y., \& Ge, 804 Q. (2019). Divergent shifts in peak photosynthesis timing of temperate and alpine

805 grasslands in China. Remote Sensing of Environment, 233, 111395.

806 https://doi.org/10.1016/j.rse.2019.111395

807 
Table 1: Grouping of phenological indicators and their representation at different levels. Shading indicates the focal organism level. (g: indicator related to plant growth; r: indicator related to reproductive period)

(Please refer to the main text for further explanation of their calculation and interpretation)

\begin{tabular}{|c|c|c|c|c|}
\hline & \multirow{2}{*}{ Indicators } & \multicolumn{2}{|c|}{ Level } \\
\hline & & & Community-level & Species-level \\
\hline \multirow{17}{*}{ Phenology } & \multirow{8}{*}{$\begin{array}{l}\text { Time } \\
\text {-related }\end{array}$} & Days after max plant growth & $g$ & \\
\hline & & Days before max plant growth & g & \\
\hline & & Greening speed & g & \\
\hline & & Browning speed & g & \\
\hline & & Ratio mid-season days & $g$ & \\
\hline & & Days until mean flowering day & & r \\
\hline & & Days until mean fruiting day & & r \\
\hline & & Days until mean dissemination day & & g \\
\hline & \multirow{9}{*}{$\begin{array}{c}\text { Performance } \\
\text {-related }\end{array}$} & Annual plant growth & g & \\
\hline & & Early plant growth & g & \\
\hline & & Mid-season plant growth & g & \\
\hline & & Late plant growth & $g$ & \\
\hline & & Flowering length & & r \\
\hline & & Fruiting length & & $r$ \\
\hline & & Max \% flowering & & $r$ \\
\hline & & Max \% fruiting & & $r$ \\
\hline & & Max \% dissemination & & $g$ \\
\hline
\end{tabular}



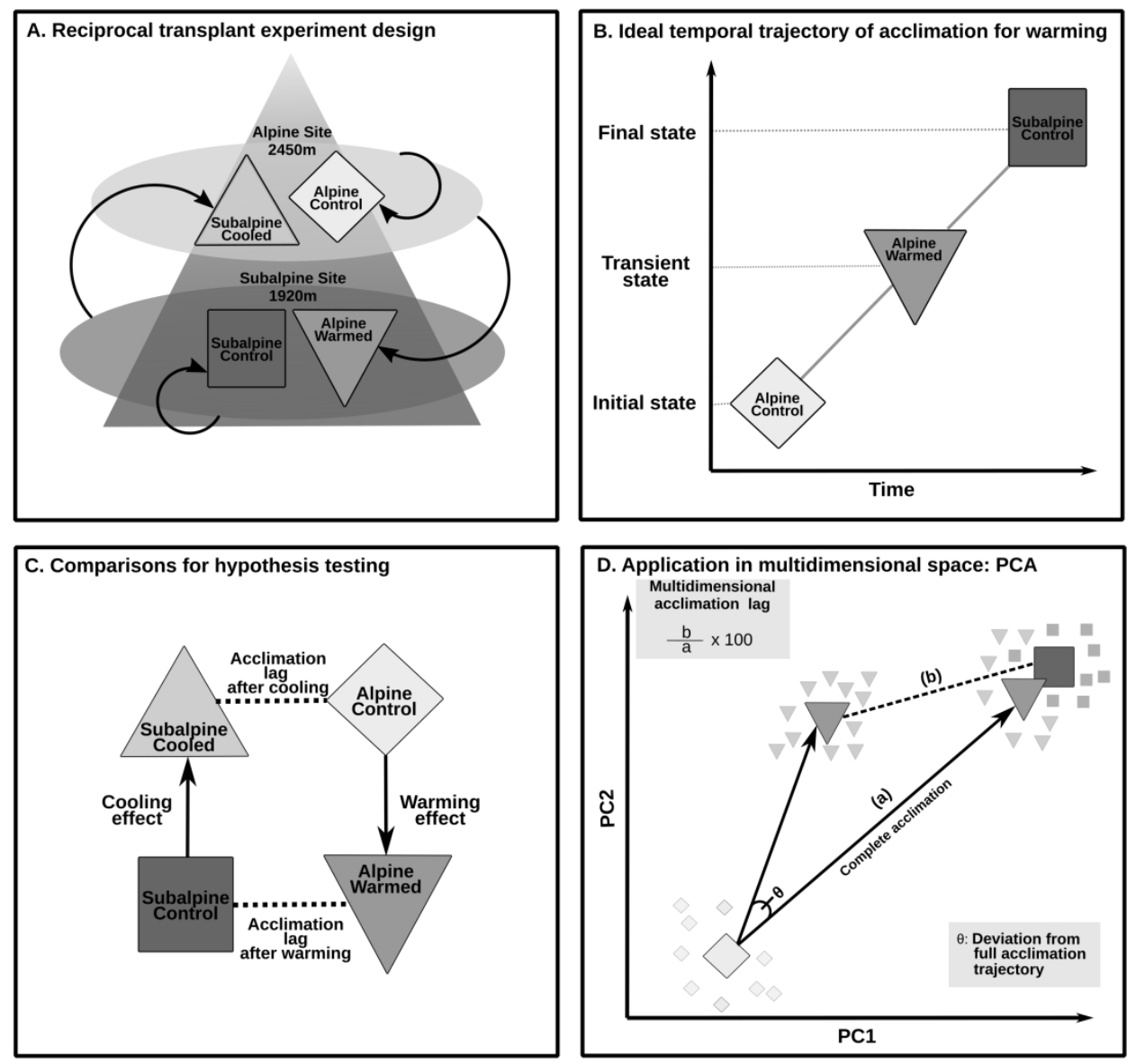

Fig. 1: (A) Schematic representation of the reciprocal transplant experiment. Arrows indicate the destination of the transplantation.

(B) Ideal temporal trajectory of acclimation to warming and the representation of the states (initial, transient and final) of the transplanted plots under the assumption that initial (final) states are at equilibrium under alpine (subalpine) conditions. (C) Treatment effects and associated comparisons of plots (custom contrast setting). Arrows indicate cooling or warming effects. Dotted lines indicate acclimation lags. For the warming effect, AlpineWarmed is contrasted to AlpineControl. For the cooling effect, SubalpineCooled is contrasted to SubalpineControl. For the acclimation lag after warming, SubalpineControl

is contrasted to AlpineWarmed. For the acclimation lag after cooling, AlpineControl is contrasted to SubalpineCooled. (D) Application of the framework to real data based on a Principal Component Analysis (PCA) in order to identify a warming effect, an acclimation lag, and a deviation from the full acclimation trajectory. 


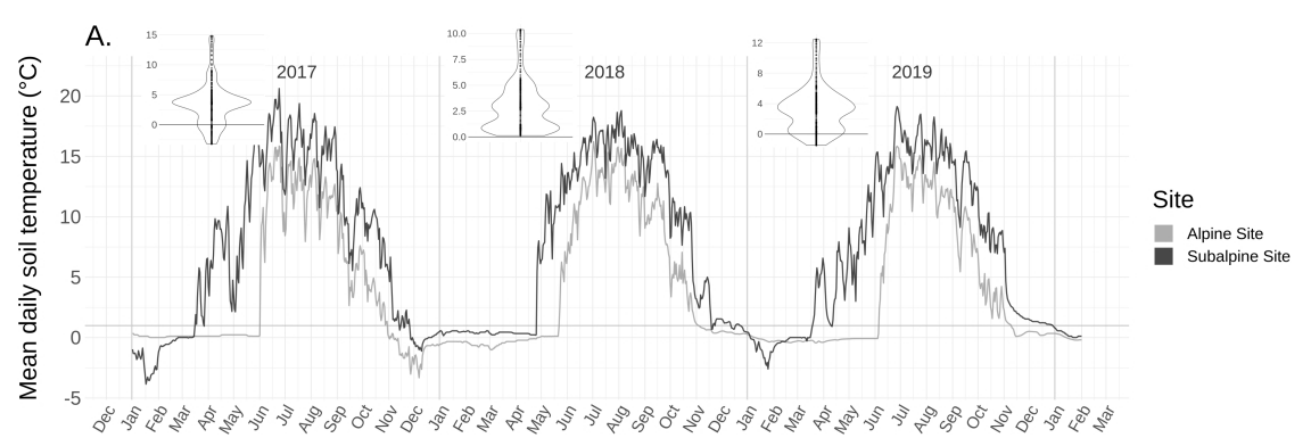

B.

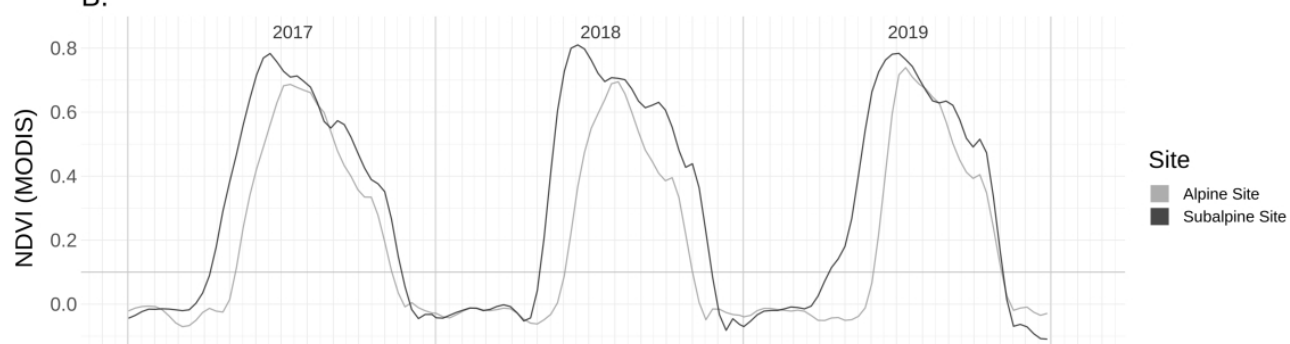

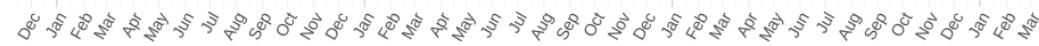

C.

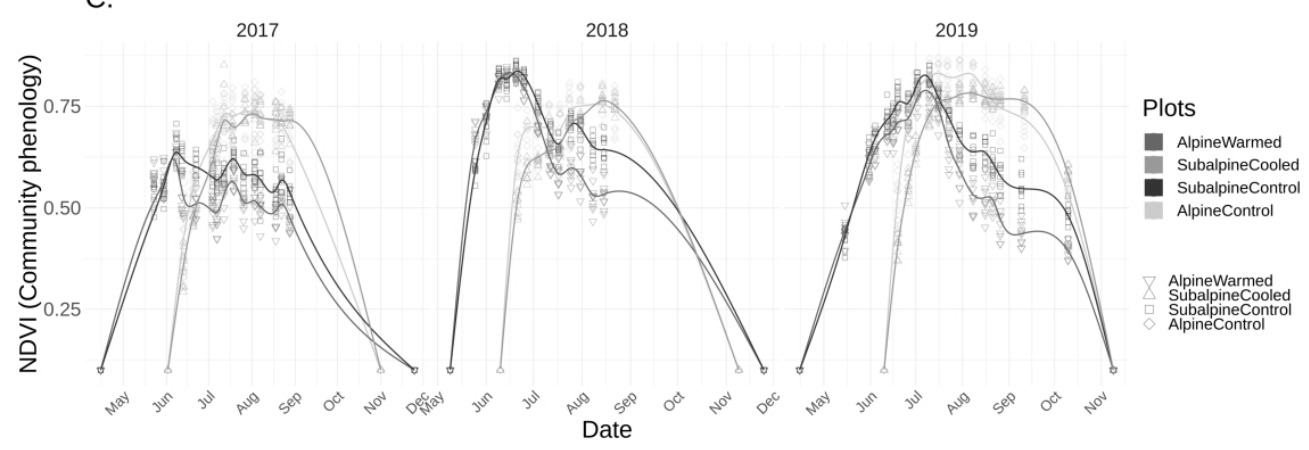

Fig. 2: (A) Soil temperature with daily soil temperature differences between the two sites for each year in the violin plots, (B) NDVI from MODIS remote-sensed data and (C) on-site NDVI plot measurements of alpine and subalpine sites. (A) and (B) were used to identify the growing seasons. (C) Transparent data points are on-site NDVI measurements for each plot. NDVI curves are daily means of interpolated and smoothed on site NDVI measurements for each treatment and control plots. (See main text Methods for details) 
A. Timing of events

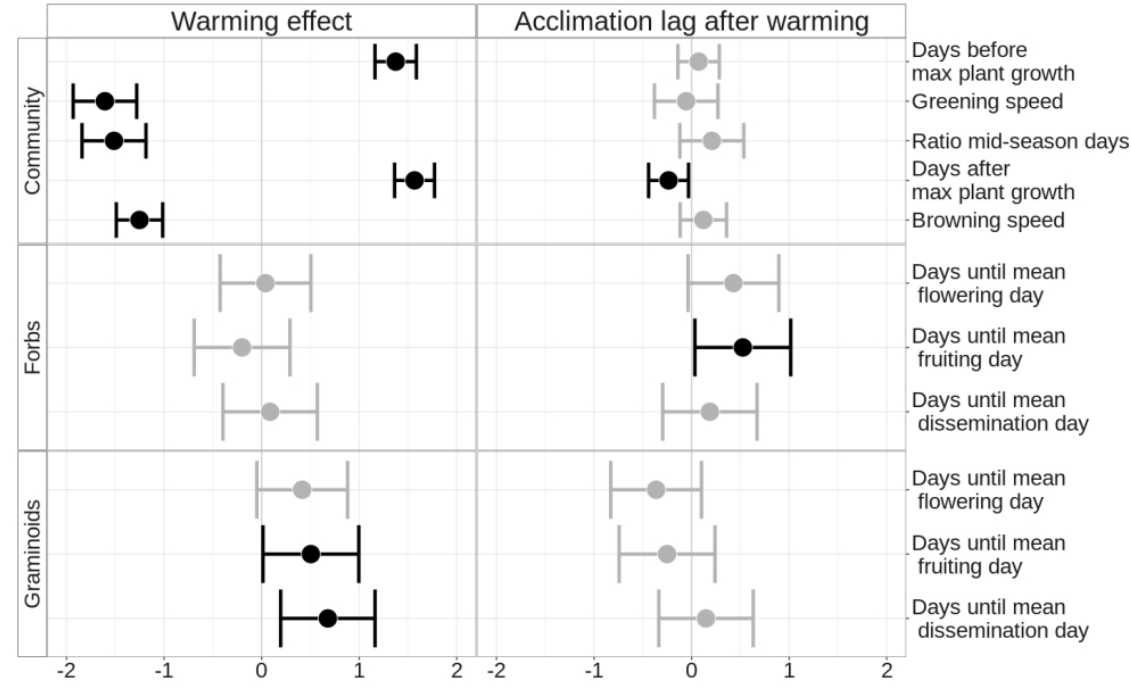

B. Performance

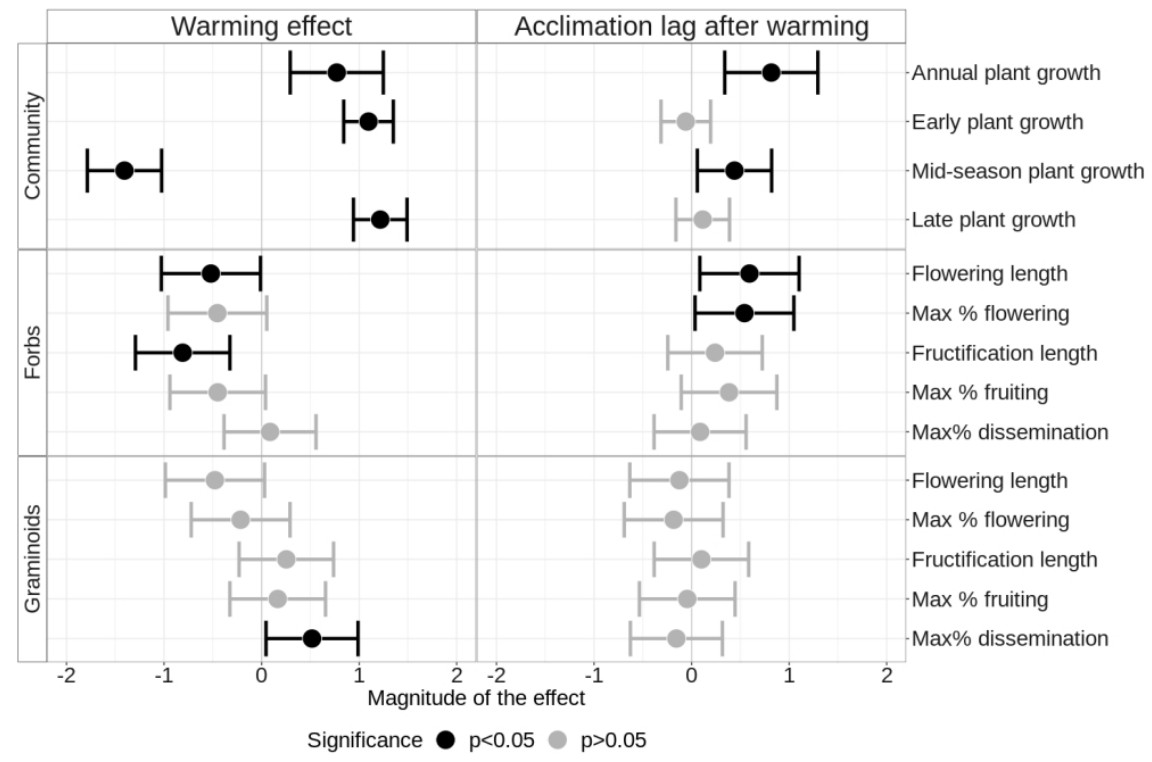

Fig. 3: Standardized effect sizes as the magnitude of warming effect and acclimation lag after warming at each focal organism level (community-level, species-level forbs and graminoids) for (A) timing of events and (B) performance related phenological indicators. Significant results are shown in black. Error bars represent 95\% confidence intervals. Warming effect: AlpineWarmed-AlpineControl. Acclimation lag after warming: SubalpineControl-AlpineWarmed. For time-related indicators, positive warming effects indicate delayed phenology. 


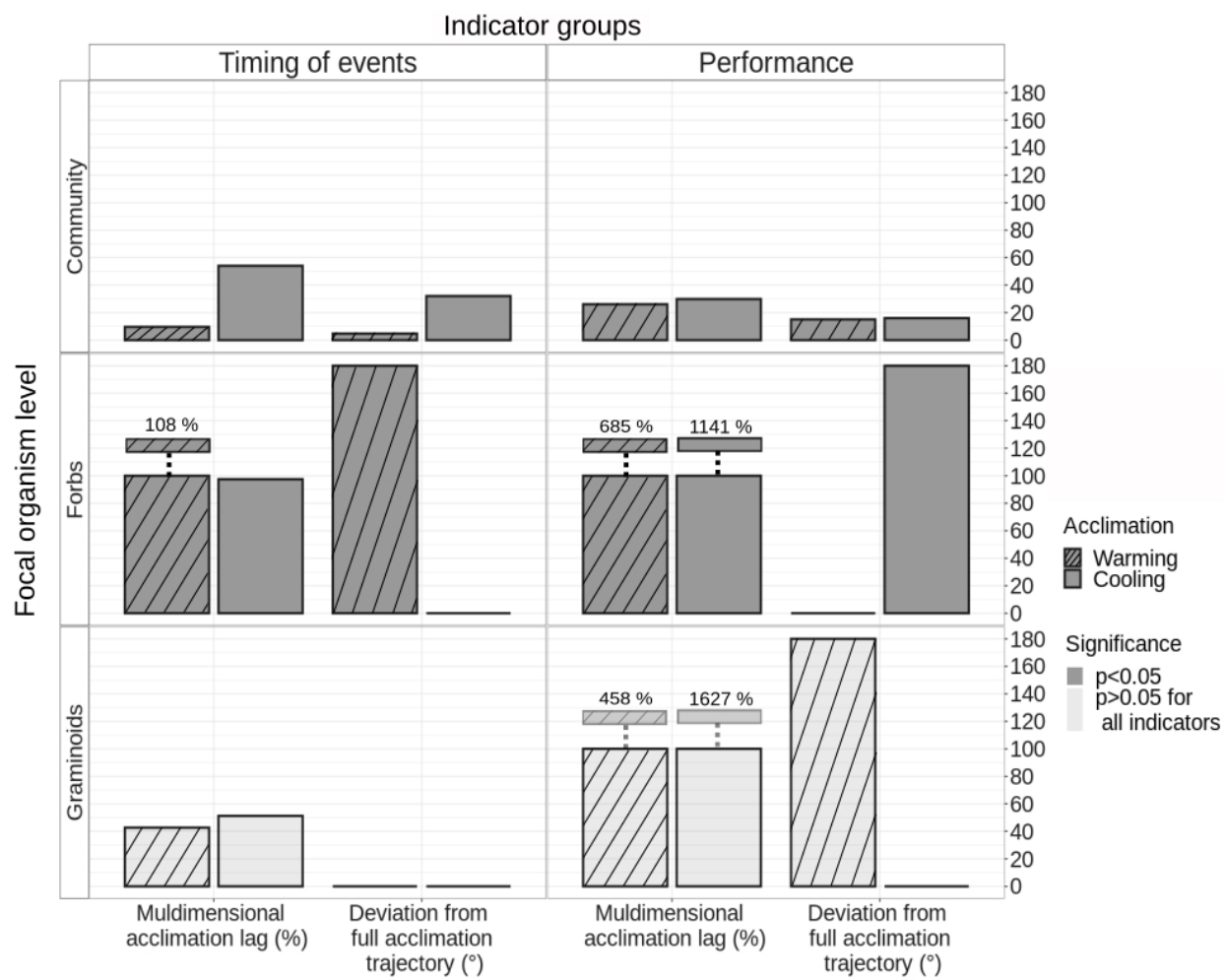

Fig. 4: Multidimensional acclimation lag and the deviation from full acclimation trajectory for both indicator groups (timing of events and performance) and all organism levels (community-level, species-level forbs and graminoids). Acclimation for warming and for cooling are shown in stripes and solid bars, respectively. When all the indicators fully acclimate, they are shown in light grey (insignificant acclimation lag in the contrast analysis, see Figure 2). 
Table S1: Soil temperature, growing season (GS) lengths, start and end dates of alpine and subalpine sites

\begin{tabular}{l|c|c|c|c|c|c|} 
Year & Site & $\begin{array}{c}\text { Soil temperature }\left({ }^{\circ} \mathbf{C}\right) \\
\text { annual }\end{array}$ & $\begin{array}{c}\text { Soil temperature }\left({ }^{\circ} \mathbf{C}\right) \\
\text { july }\end{array}$ & $\begin{array}{c}\text { GS length } \\
\text { Season start }\end{array}$ Season end \\
2017 & alpine & 3.74 & 12.35 & 152 & $2017-06-02$ & $2017-11-01$ \\
2017 & subalpine & 7.16 & 16.02 & 224 & $2017-04-15$ & $2017-11-25$ \\
2018 & alpine & 4.42 & 13.85 & 152 & $2018-06-10$ & $2018-11-09$ \\
2018 & subalpine & 7.34 & 16.66 & 200 & $2018-05-09$ & $2018-11-25$ \\
2019 & alpine & 3.88 & 13.40 & 152 & $2019-06-10$ & $2019-11-09$ \\
2019 & subalpine & 7.14 & 16.17 & 208 & $2019-04-15$ & $2019-11-09$
\end{tabular}


Table S2: Focal species' descriptive table

\begin{tabular}{|c|c|c|c|c|c|c|c|c|c|}
\hline Species & Growth form & Origin & Flower onset & $\begin{array}{l}\text { Observations (\%) } \\
<10 \text { individuals }\end{array}$ & Cover class & $\begin{array}{c}\text { Ellenberg moisture } \\
\text { indicator }\end{array}$ & $\begin{array}{l}\text { Ellenberg moisture } \\
\text { indicator variation }\end{array}$ & $\begin{array}{c}\text { Ellenberg temperature } \\
\text { indicator }\end{array}$ & $\begin{array}{l}\text { Ellenberg temperature } \\
\text { indicator variation }\end{array}$ \\
\hline Geum montanum $L$. & forb & alpine & May & 66.83 & 2 & 3.0 & small variation (I) & 1.5 & small variation (I) \\
\hline Potentilla aurea $L$. & forb & alpine & June & 2.51 & 3 & 2.5 & small variation (I) & 1.5 & large variation (II) \\
\hline Trifolium alpinum & forb & alpine & June & 1.13 & 4 & 2.5 & small variation (I) & 1.5 & small variation (I) \\
\hline Poa alpina $L$. & graminoid & alpine & June & 2.13 & 2 & 3.5 & large variation (II) & 1.5 & large variation (II) \\
\hline Carex sempervirens Vill. & graminoid & both & June & 1.32 & 4 & 2.0 & small variation (I) & 1.5 & small variation (I) \\
\hline Festuca nigrescens Lam. & graminoid & both & June & 2.32 & 4 & 2.5 & large variation (II) & 2.5 & large variation (II) \\
\hline Centaurea uniflora & forb & subalpine & July & 10.65 & 3 & 2.0 & small variation (I) & 2.0 & small variation (I) \\
\hline Helianthemum nummularium (L.) Miller & forb & subalpine & June_May & 4.64 & 2 & 2.0 & small variation (I) & 1.5 & small variation (I) \\
\hline Meum athamanticum Jacq. & forb & subalpine & May & 1.63 & 3 & 2.5 & small variation (I) & 2.5 & small variation (I) \\
\hline Patzkea paniculata (L.) G. H. Loos & graminoid & subalpine & June & 7.02 & 4 & 2.0 & small variation (I) & 3.0 & small variation (I) \\
\hline
\end{tabular}

*Flower onset according to the local plant functional trait database Androsace (Thuiller et al., unpublished)

** Observations (\%): Percentage of observations when only less than 10 individuals are recorded over the total number of observations along the whole growing season.

${ }^{* * *}$ Cover class according to Braun-Blanquet classes (2: 6-25\%, 3: 26-50\%, 4: 51-75\% cover). Inventories were done at each site in 2016.

Thuiller et al . (unpublished) Androsace Plant Functional Traits Database, Laboratoire d'Ecologie Alpine, 38610 Gières, France Braun-Blanquet J., Roussine N. \& Nègre R., (1952) Les groupements végétaux de la France méditerranéenne. Dir. Carte Group. Vég. Afr. Nord, CNRS, 292 p. 
Table S3: Changes in annual air and soil temperature $\left({ }^{\circ} \mathrm{C}\right)$ and in community-level phenological indicators (NDVI). Historical changes are between 1960-2016 for temperature and between 2000-2016 for phenological indicators. Experimental changes are between 2016 observed data and average of three-years experimental outputs. The last column shows how much change was already taken due to ongoing climate warming in comparison to the experimental warming. The sign difference indicates that the changes are in different directions.

\begin{tabular}{l|c|c|c}
\multicolumn{1}{c}{ Indicator } & Historical change (HC) & Experimental change (EC) & HC relative to EC (\%) \\
Annual air temprature & 1.20000 & NA & 25.00 \\
Annual soil temprature & 0.80000 & 3.20000 & 1.51 \\
Growing Season Length & 0.73383 & 48.61855 & 26.75 \\
Annual plant growth & 4.78956 & 17.90705 & 103.01 \\
Early plant growth & 4.35445 & 4.22724 & -6.12 \\
Late plant growth & -1.14368 & 18.68990 & -33.61 \\
Mid-season plant growth & 1.65843 & -4.93400 & -216.07 \\
Greening speed & -0.00121 & 0.00056 & -44.95 \\
Browning speed & 0.00098 & -0.00218 & 111.24 \\
Greening days & 7.30226 & 6.56413 & -14.05 \\
Browning days & -6.94135 & 49.42147 & 0.93 \\
Mid-season ratio & -0.00087 & -0.09379 & \\
\multicolumn{2}{|l}{} & & \\
*Daily mean air temperature data were extracted from SAFRAN-CROCUS-MEPRA meteorological \\
model developed by Météo-France for the French Alps. NDVI data were extracted from MODIS remote \\
sense time series data for historical changes. Changes were calculated from predicted values of a linear \\
model between indicator values and years. Remote sense data were prepared and phenological \\
indicators were calculated in the same way as it was elaborated on the main manuscript. Annual air \\
temperature for EC is missing as the experimental measurements have gaps in the data to damaged \\
probes on the field site.
\end{tabular}




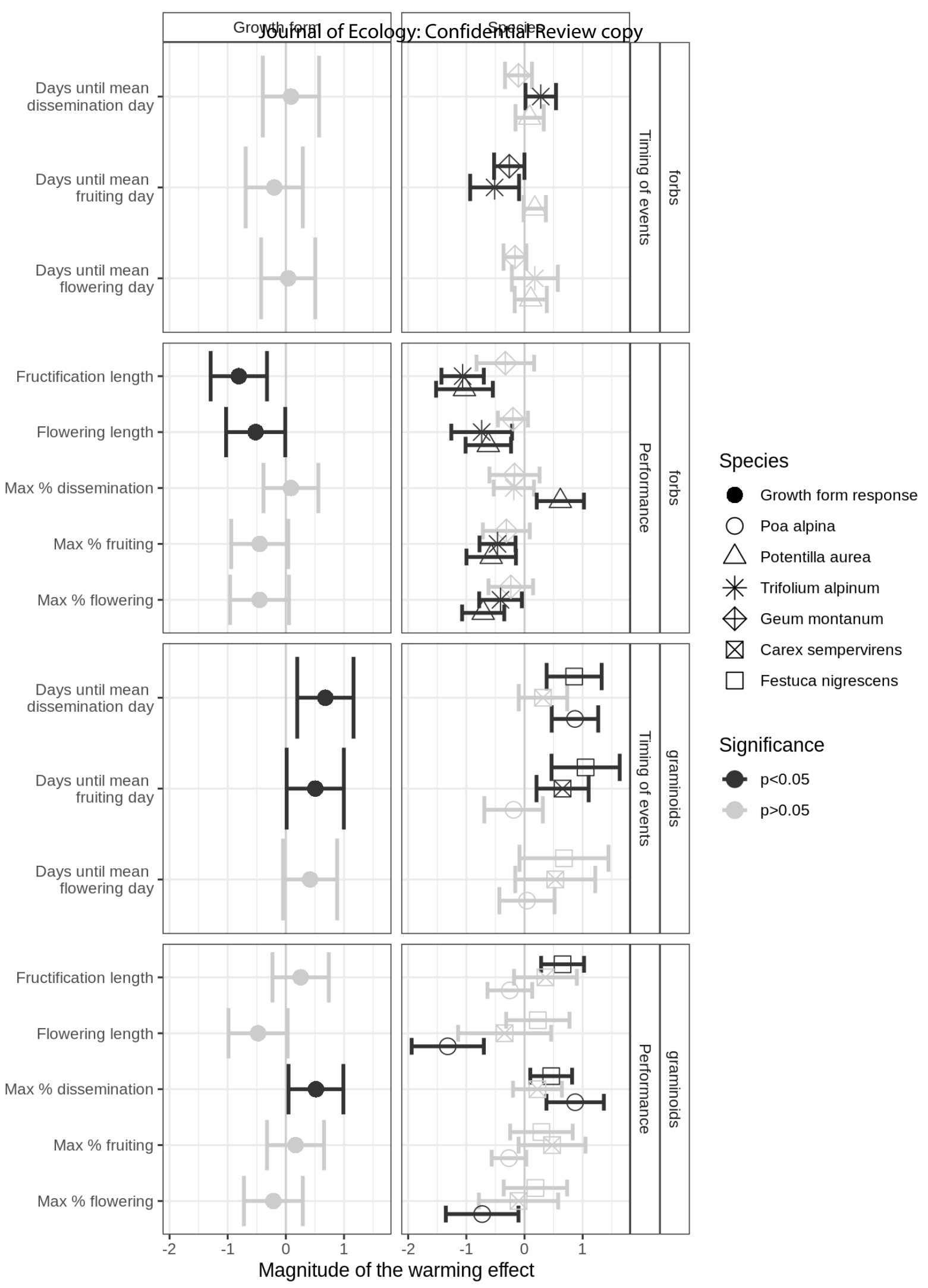

Page 44 of 60 


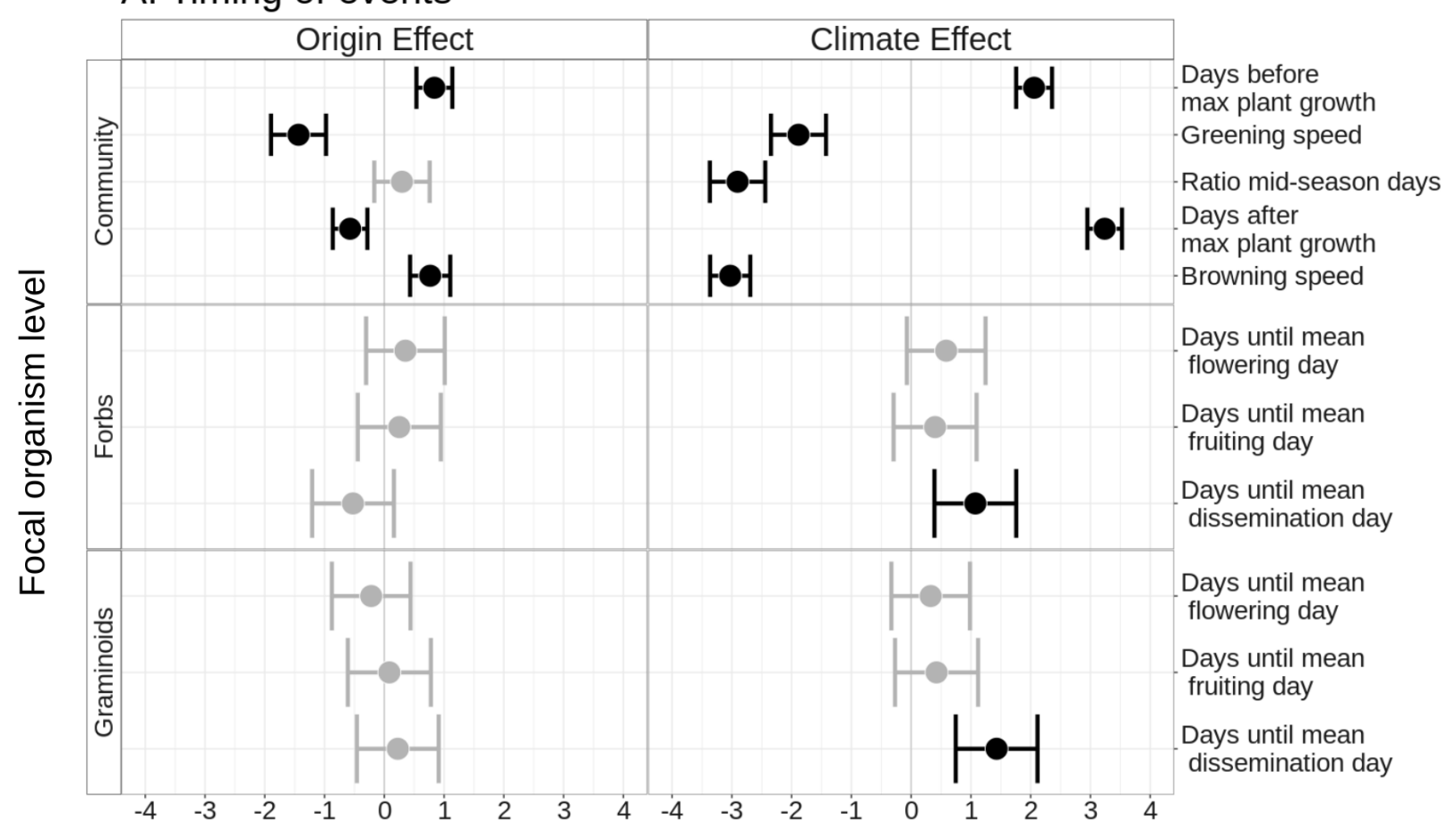

\section{B. Performance}

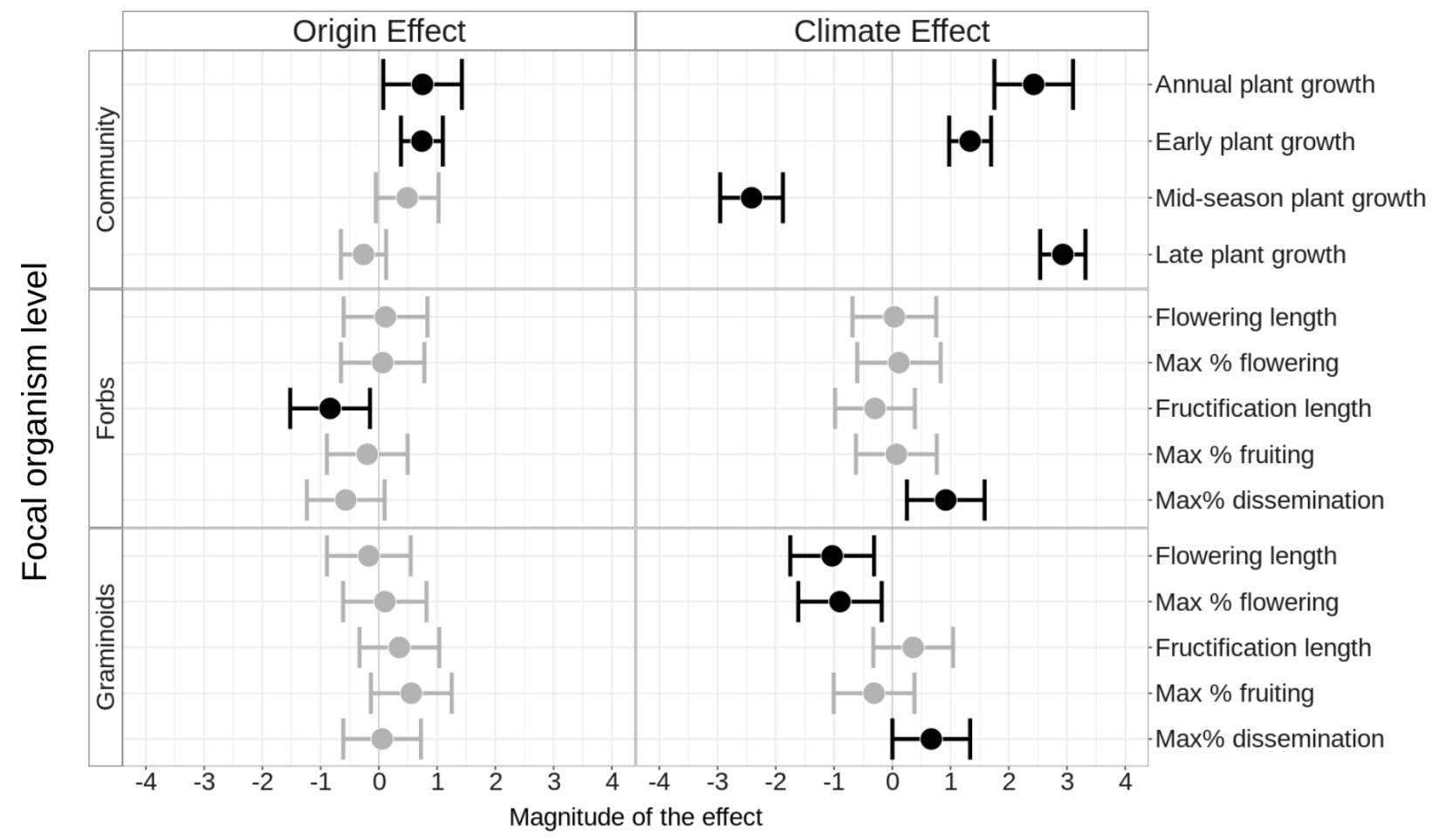

Significance $\bigcirc p<0.05 \bigcirc p>0.05$

Figure S2: Standardized effect sizes as the magnitude of origin and climate effects at each focal organism level (community level, species level forbs and graminoids) for (A) timing of events and (B) performance related phenological indicators. Significant results are shown in black. Error bars represent 95\% confidence intervals. Origin effect: Subalpine origin - Alpine origin; Climate effect: Subalpine site - Alpine site. 
A. Timing of events Journal of Ecology: Confidential Review copy

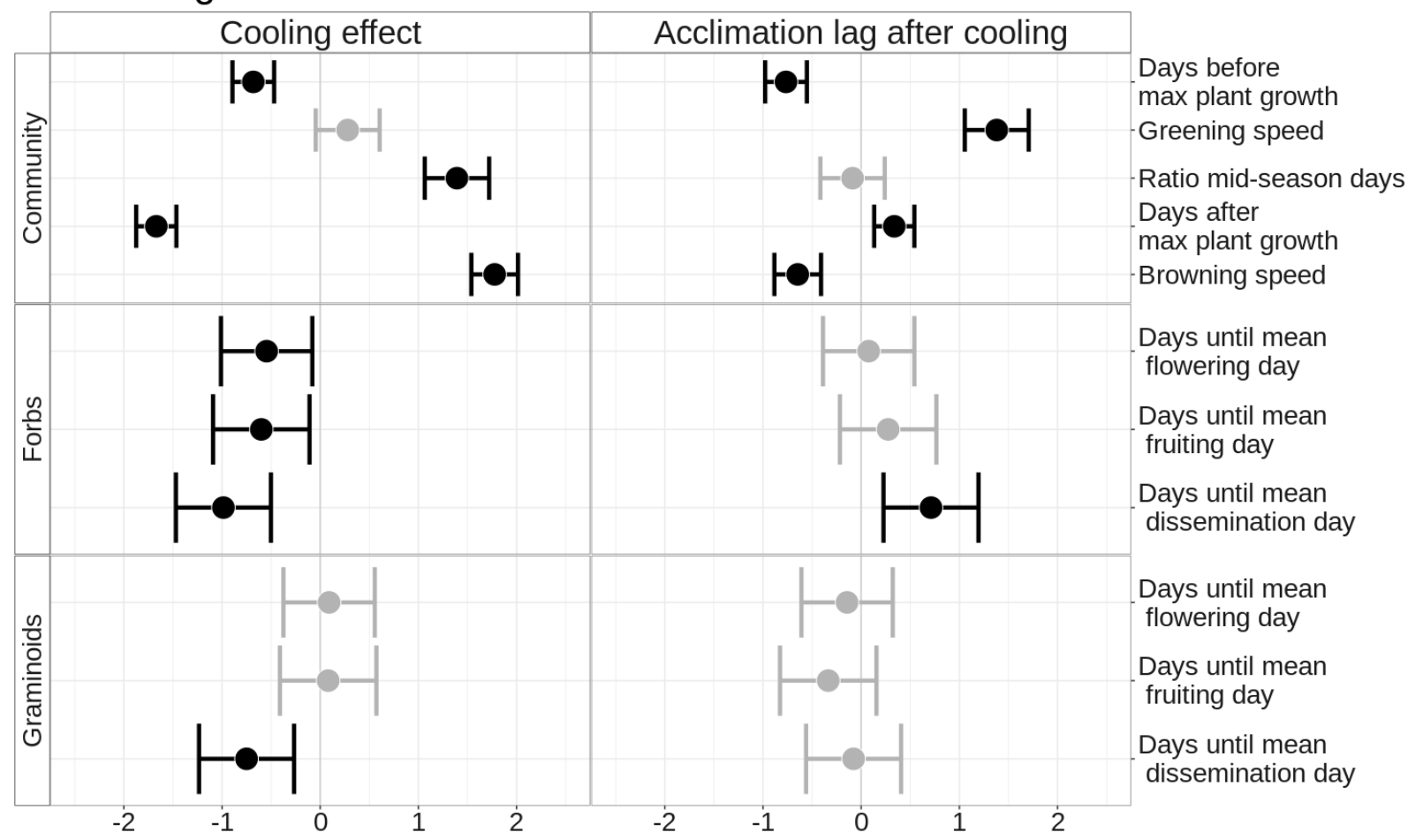

B. Performance

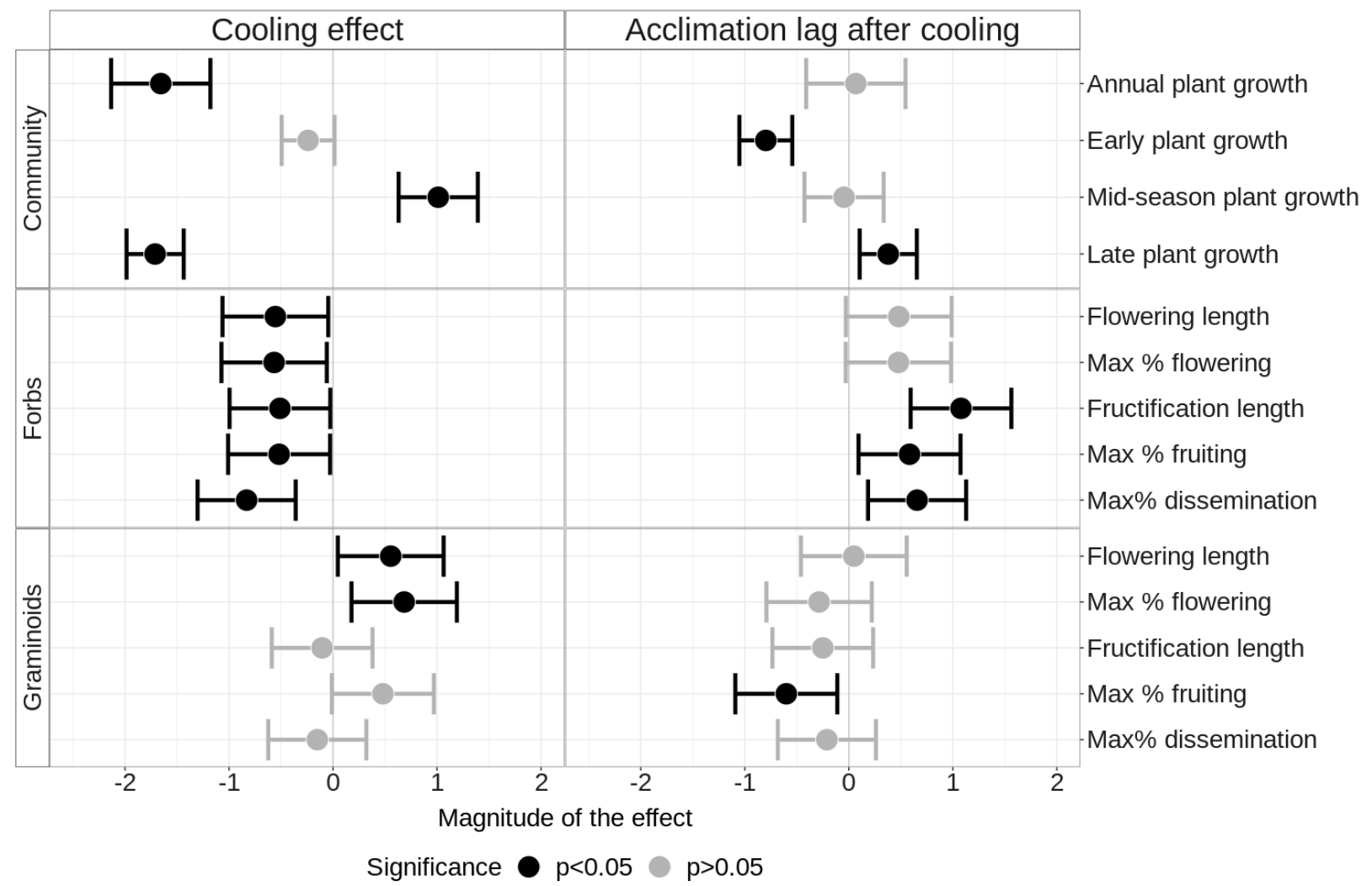

Figure S3: Standardized effect sizes as the magnitude of cooling effect and acclimation lag after cooling at each focal organism level (community level, species level forbs and graminoids) for (A) timing of events and (B) performance related phenological indicators. Significant results are shown in black. Error bars represent $95 \%$ confidence intervals. Warming effect:

AlpineWarmed-AlpineControl. Acclimation lag after warming: SubalpineControl-AlpineWarmed. 


\section{A) Community}
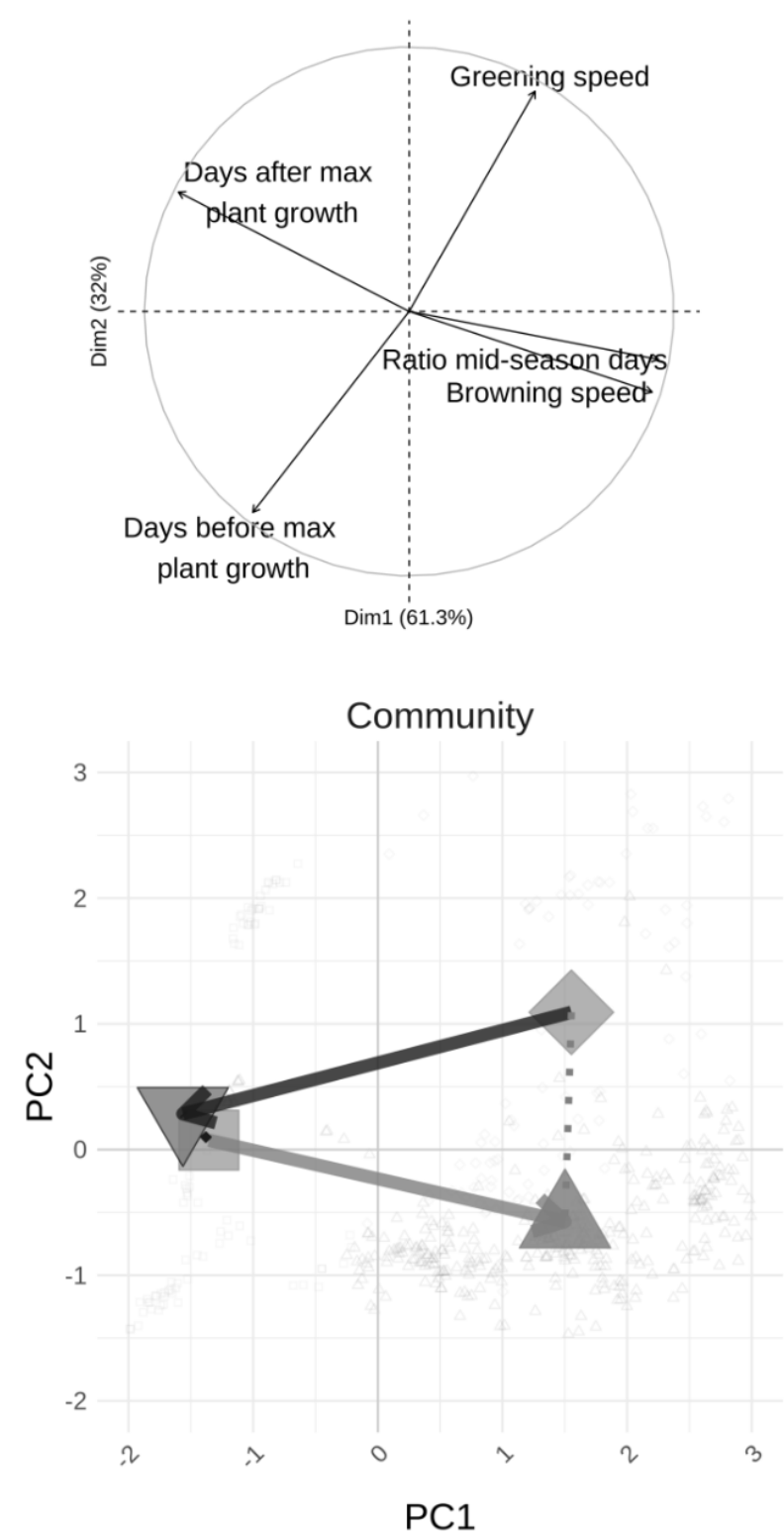

B) Forbs

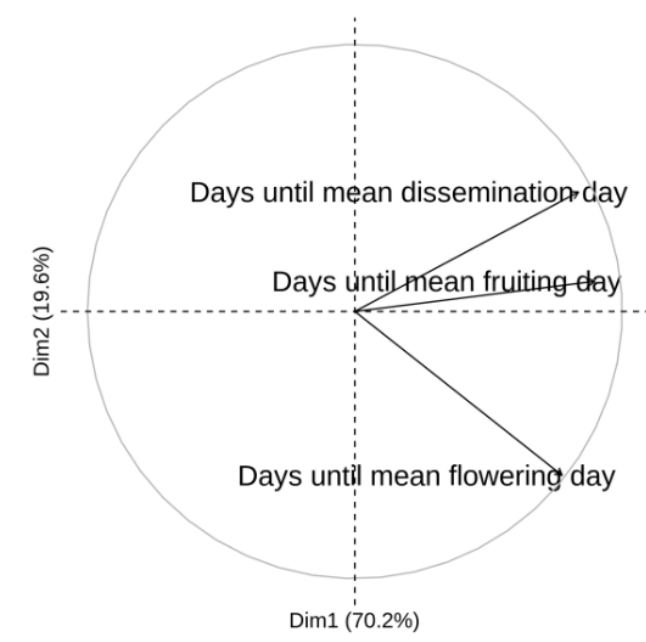

Species-Forbs

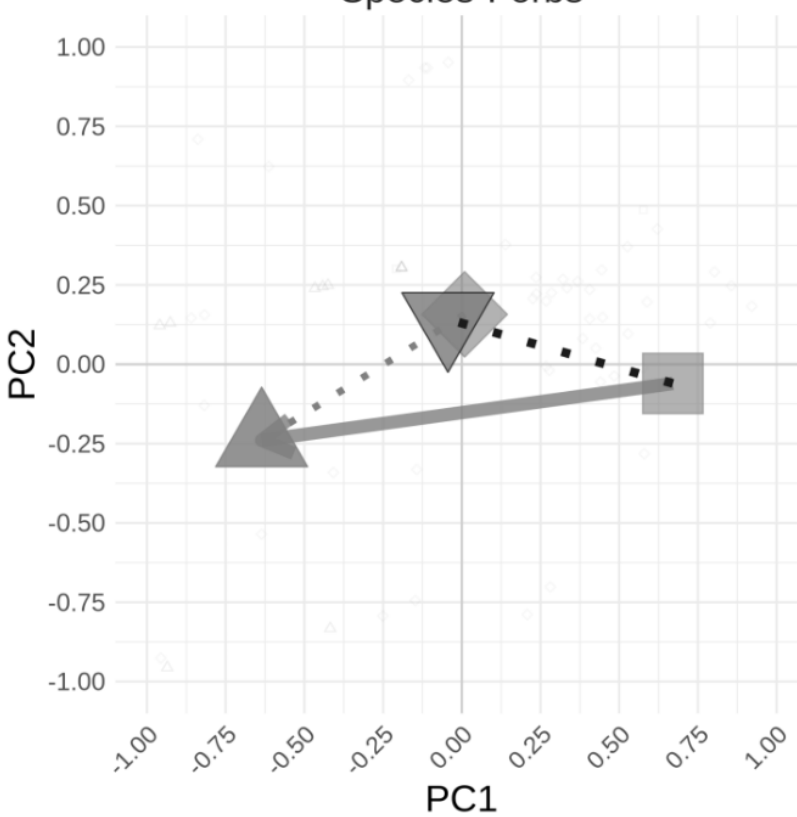

C) Graminoids

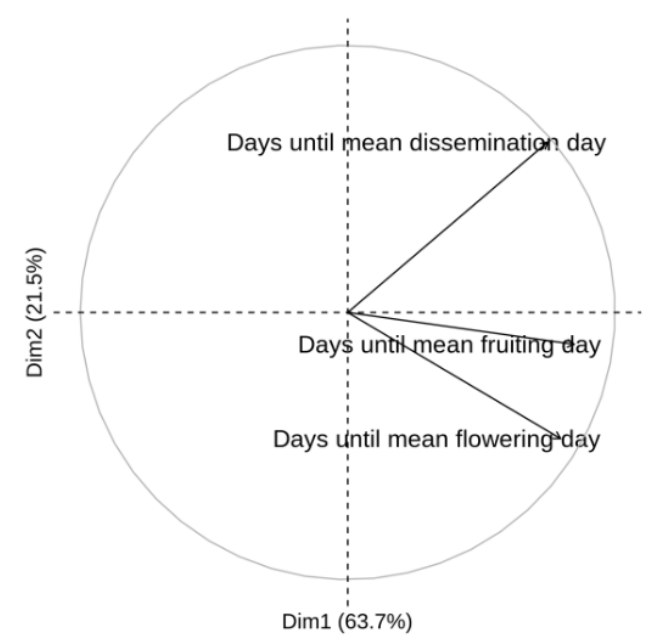

Species-Graminoids

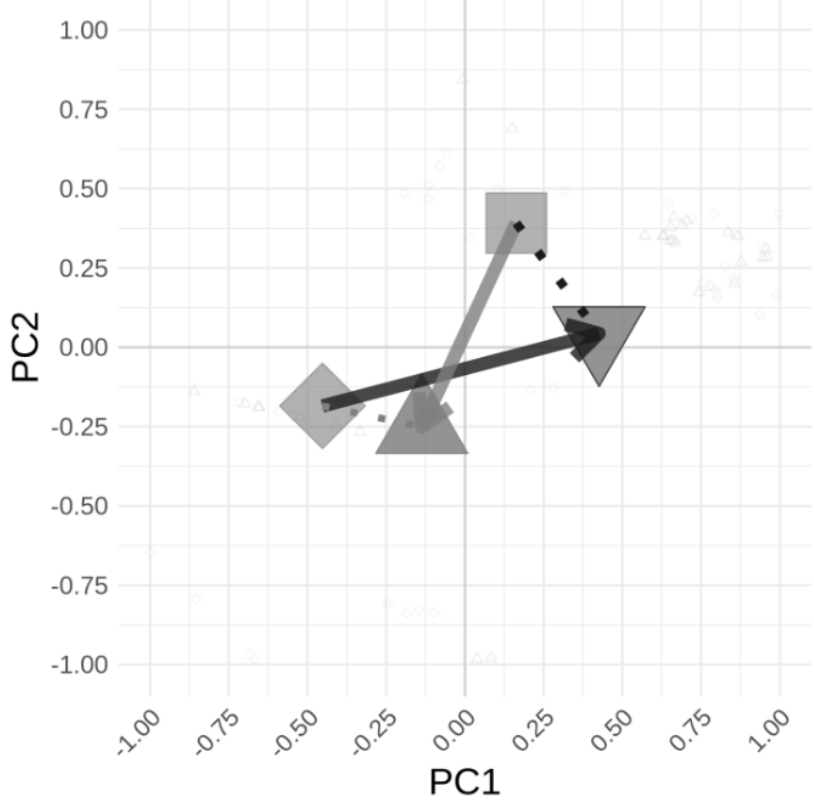

Warming effect $\because+\cdots=$ Acclimation lag after warming Cooling effect

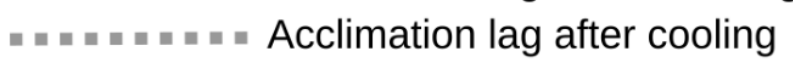




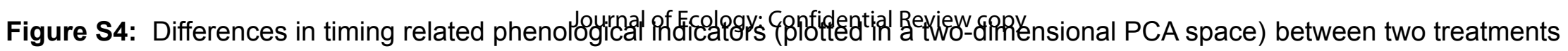
and controls (AlpineWarmed, SubalpineCooled, AlpineControl and SubalpineControl) at the community (A) and the species level (forbs (B) and gramminoids (C)). Straight arrows highlight warming (AlpineWarmed-AlpineControl) or cooling effect

(SubalpineCooled-SubalpineControl) and dotted lines the acclimation lag after warming (SubalpineControl-AlpineWarmed) or cooling (AlpineControl-SubalpineCooled). Here, the responses over 3 years were shown (diamond: AlpineControl, square: SubalpineControl, inverse triangle: AlpineWarmed, triangle: SubalpineCooled). For further analyses, the first two PCs were selected from (A) and only the first $P C$ from $(B)$ and $(C)$. 


\section{A) Community}
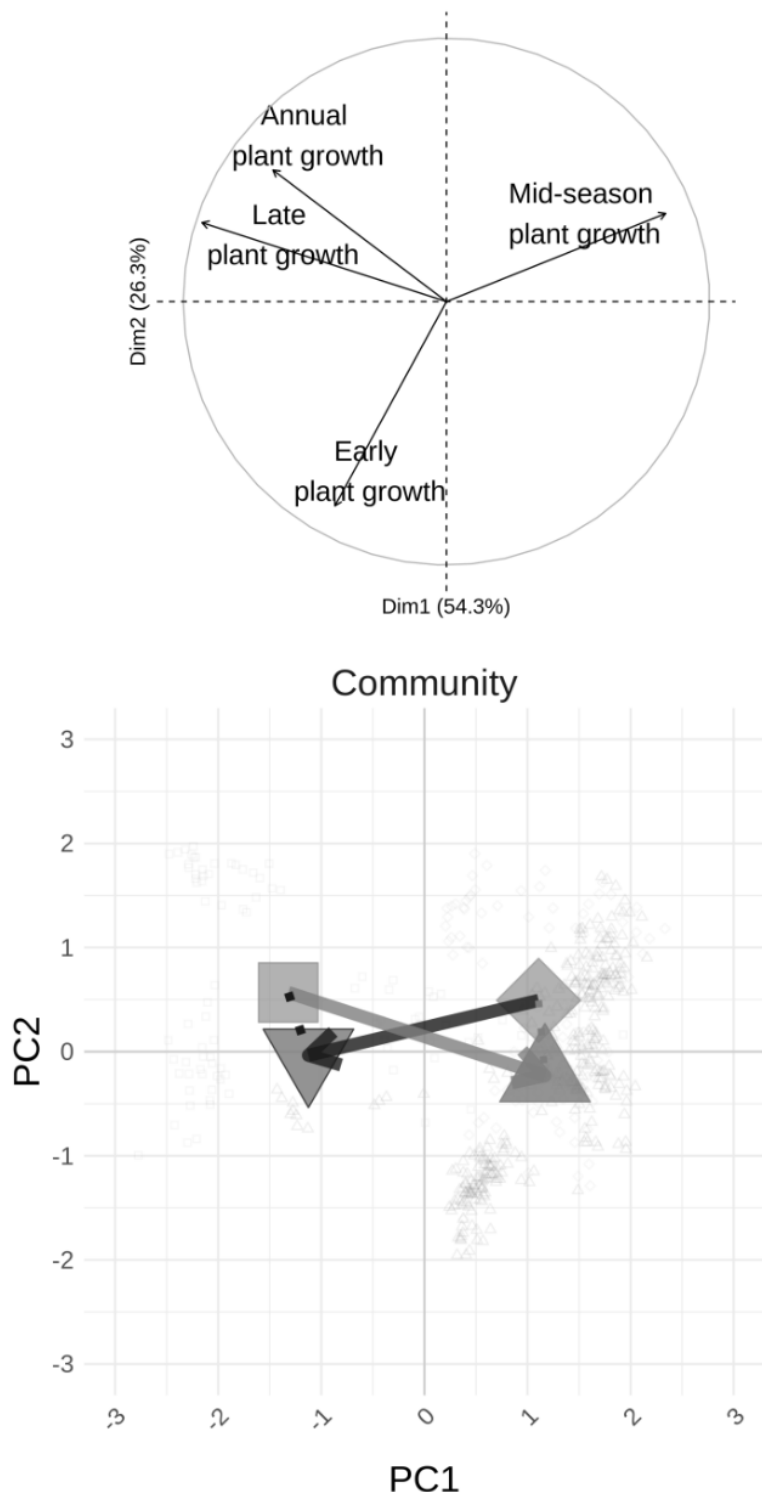

B) Forbs

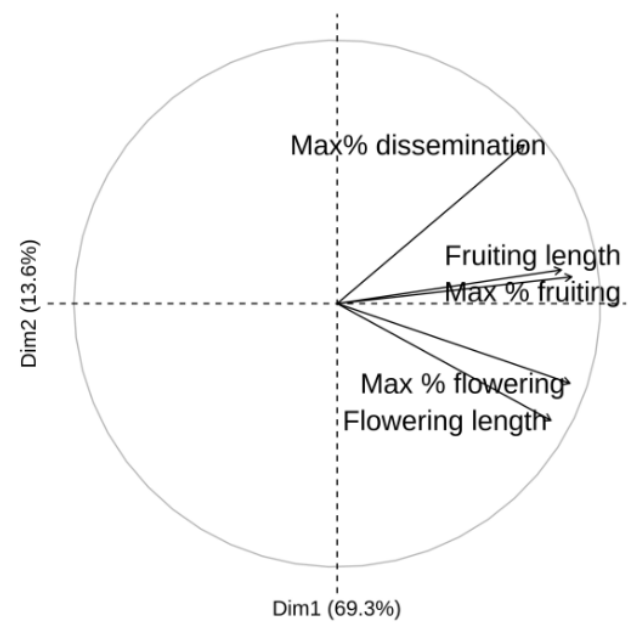

Species-Forbs

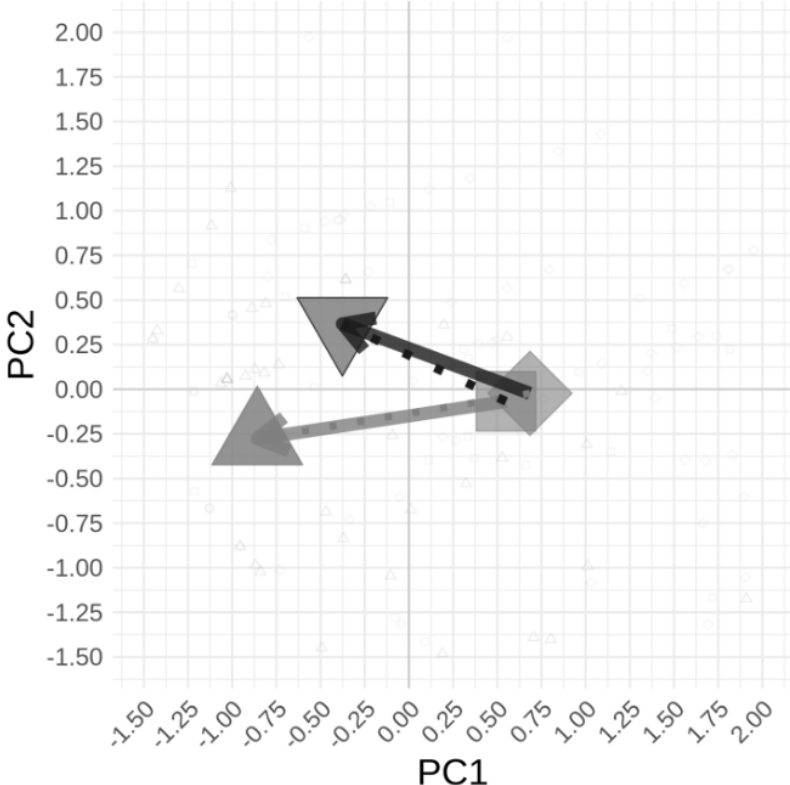

C) Graminoids

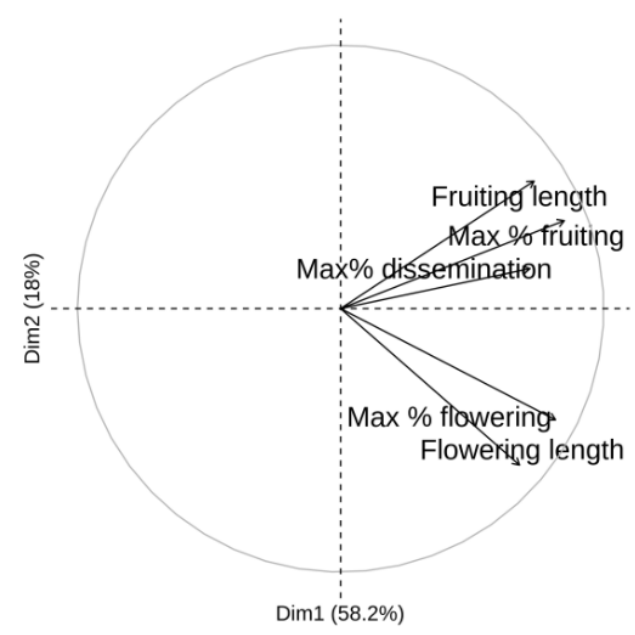

Species-Graminoids

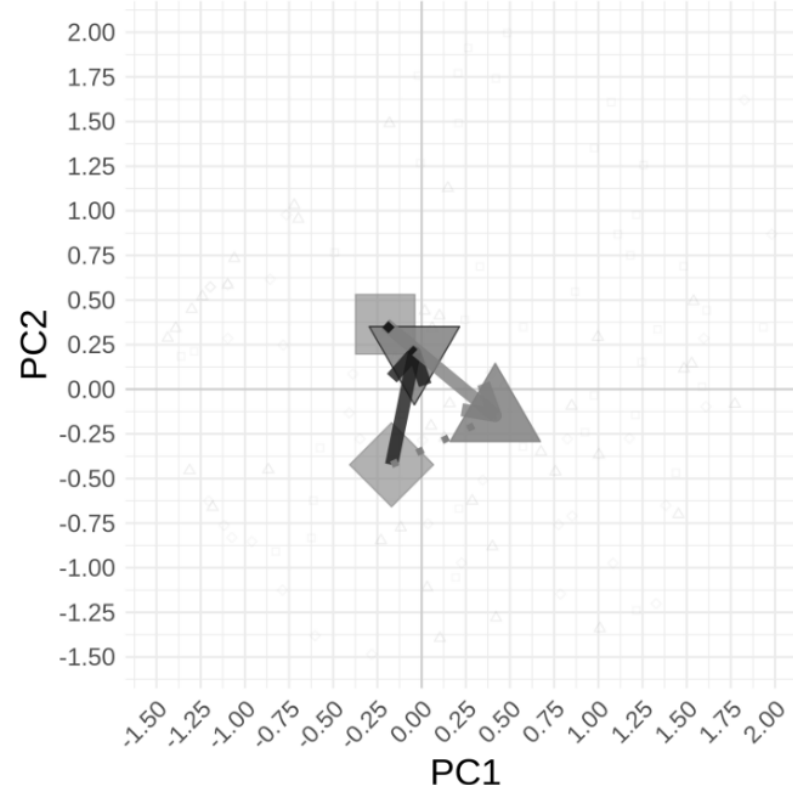

Warming effect $: \cdots \cdot$ Acclimation lag after warming Cooling effect 
Figure S5: Differences in performance related phenological indicators (plotted in a two-dimensional PCA space) between two treatments and controls (AlpineWarmed, SubalpineCooled, AlpineControl and SubalpineControl) at the community $(A)$ and the species level (forbs (B) and gramminoids (C)). Straight arrows highlight warming (AlpineWarmed-AlpineControl) or cooling effect (SubalpineCooled-SubalpineControl) and dotted lines the acclimation lag after warming (SubalpineControl-AlpineWarmed) or cooling (AlpineControl-SubalpineCooled). Here, the responses over 3 years were shown (diamond: AlpineControl, square: SubalpineControl, inverse triangle: AlpineWarmed, triangle: SubalpineCooled). For further analyses, the first two PCs were selected from (A) and only the first $P C$ from $(B)$ and $(C)$. 


\section{A) Community}
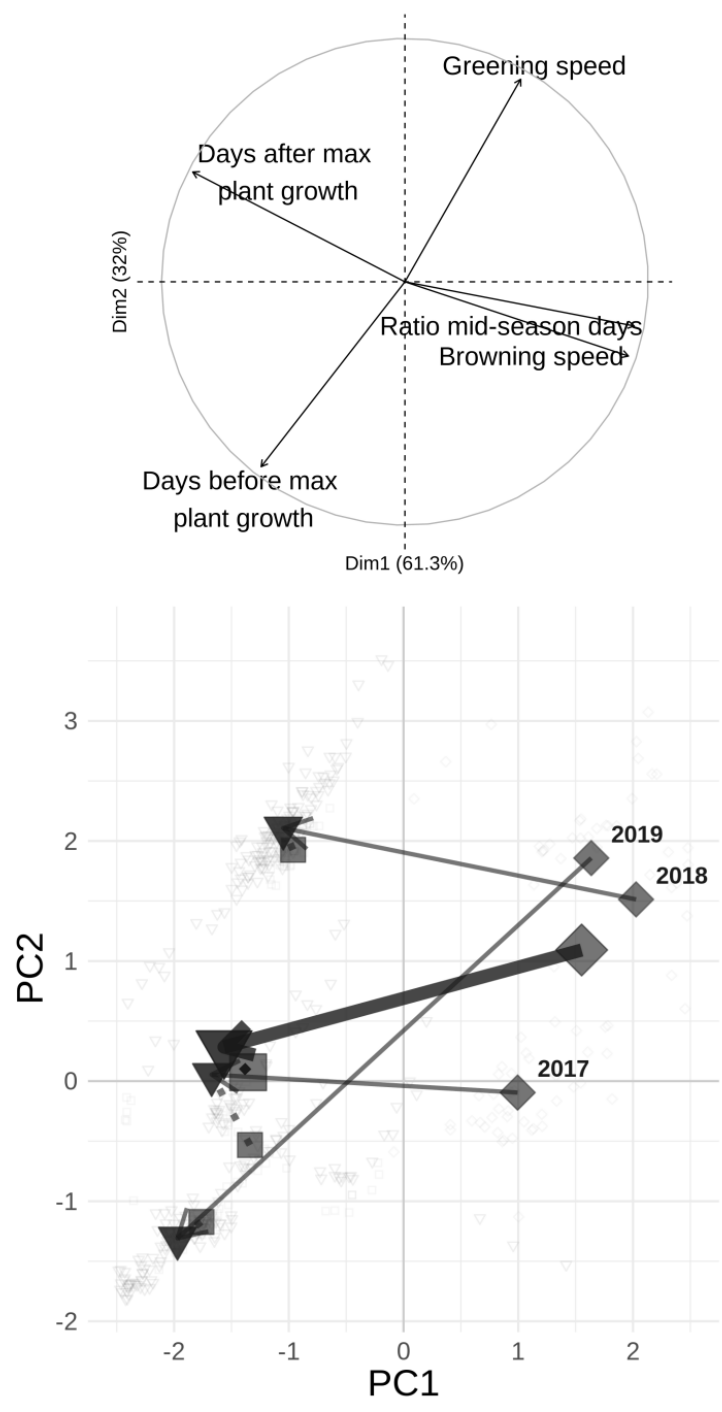

B) Forbs
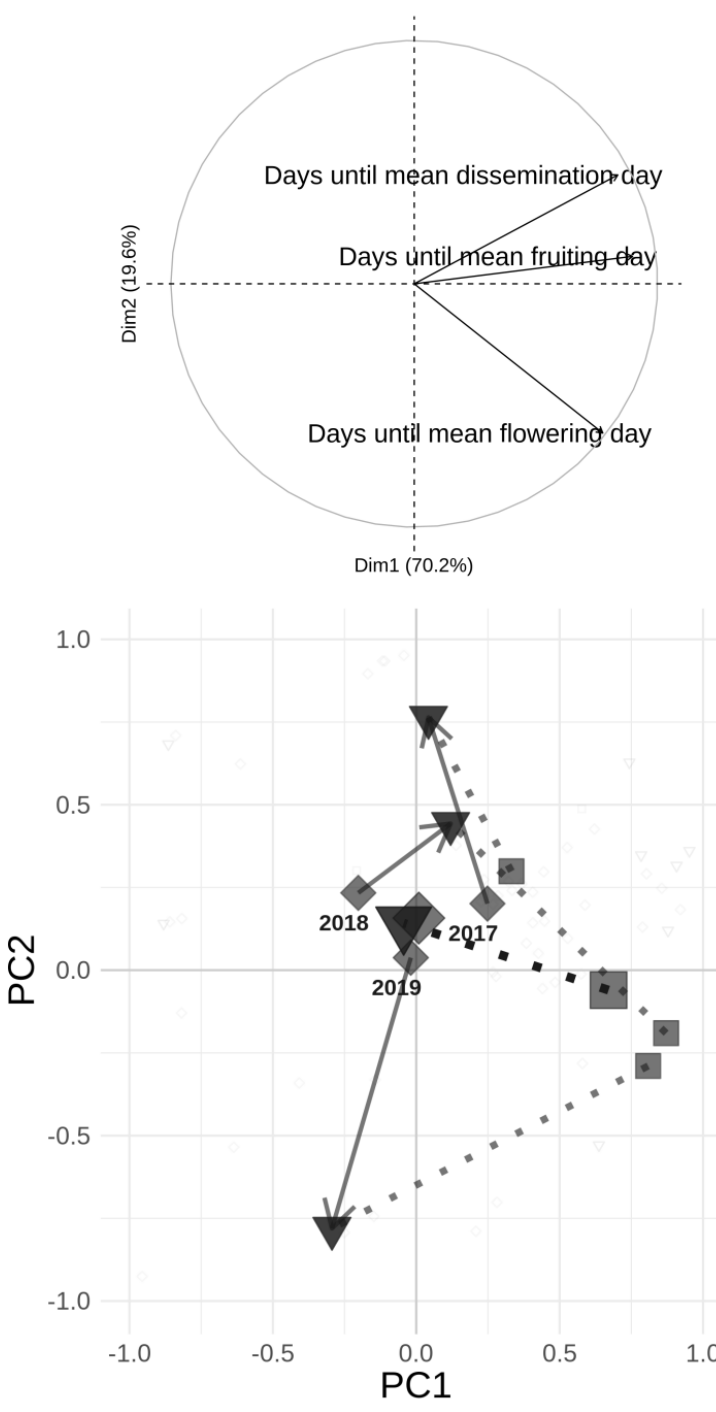

C) Graminoids
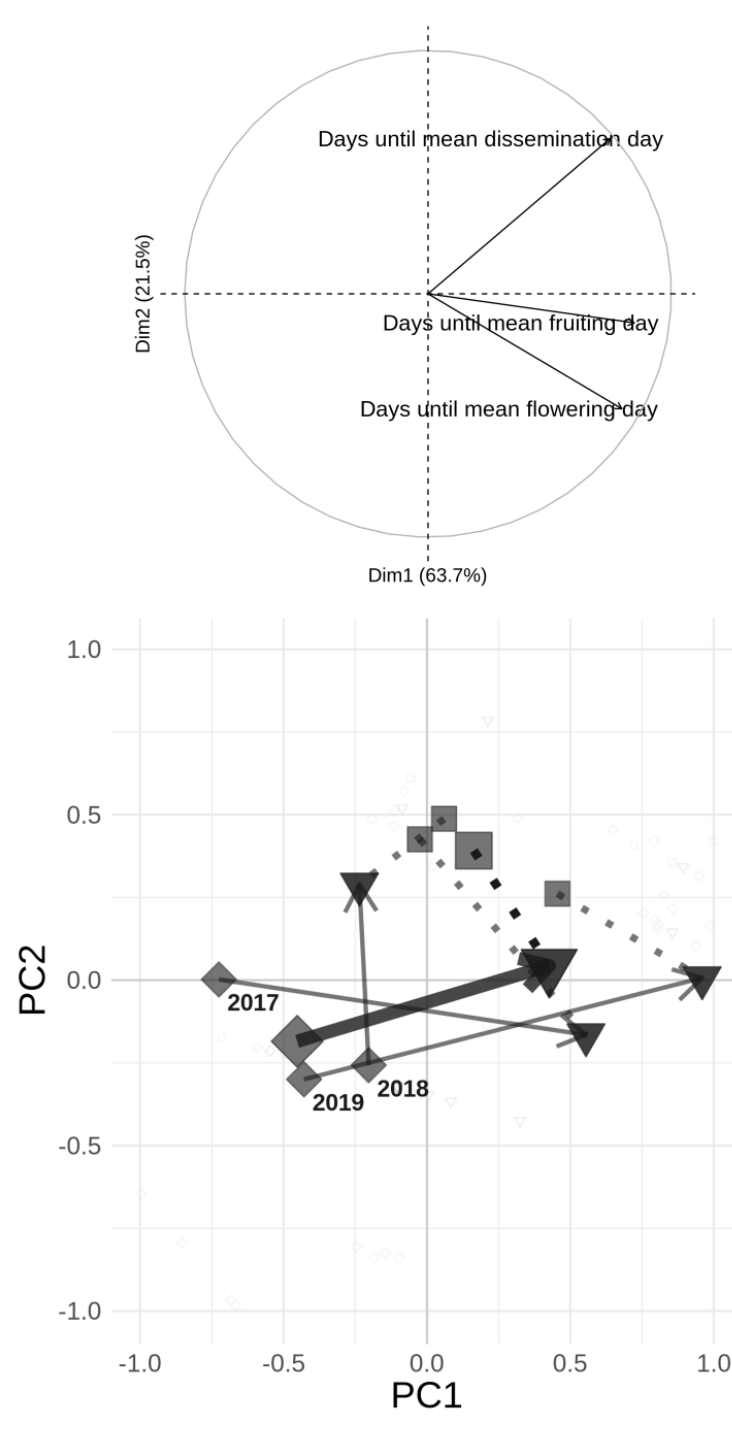
Figure S6: Differences in timing related phenological indicators (plotted in a two-dimensional PCA space) between the three treatments (AlpineWarmed, AlpineControl and SubalpineControl) at the community (A) and the species level (forbs (B) and gramminoids (C)). Straight arrows highlight warming effect (AlpineWarmed-AlpineControl) and dotted lines the acclimation lag after warming (SubalpineControl-AlpineWarmed). Thicker lines indicate the overall response for three years. Thinner lines indicate annual response. (diamond: AlpineControl, square: SubalpineControl, inverse triangle: AlpineWarmed). For further analyses, the first two $P C$ s were selected from $(A)$ and only the first PC from (B) and (C). 


\section{A) Community}
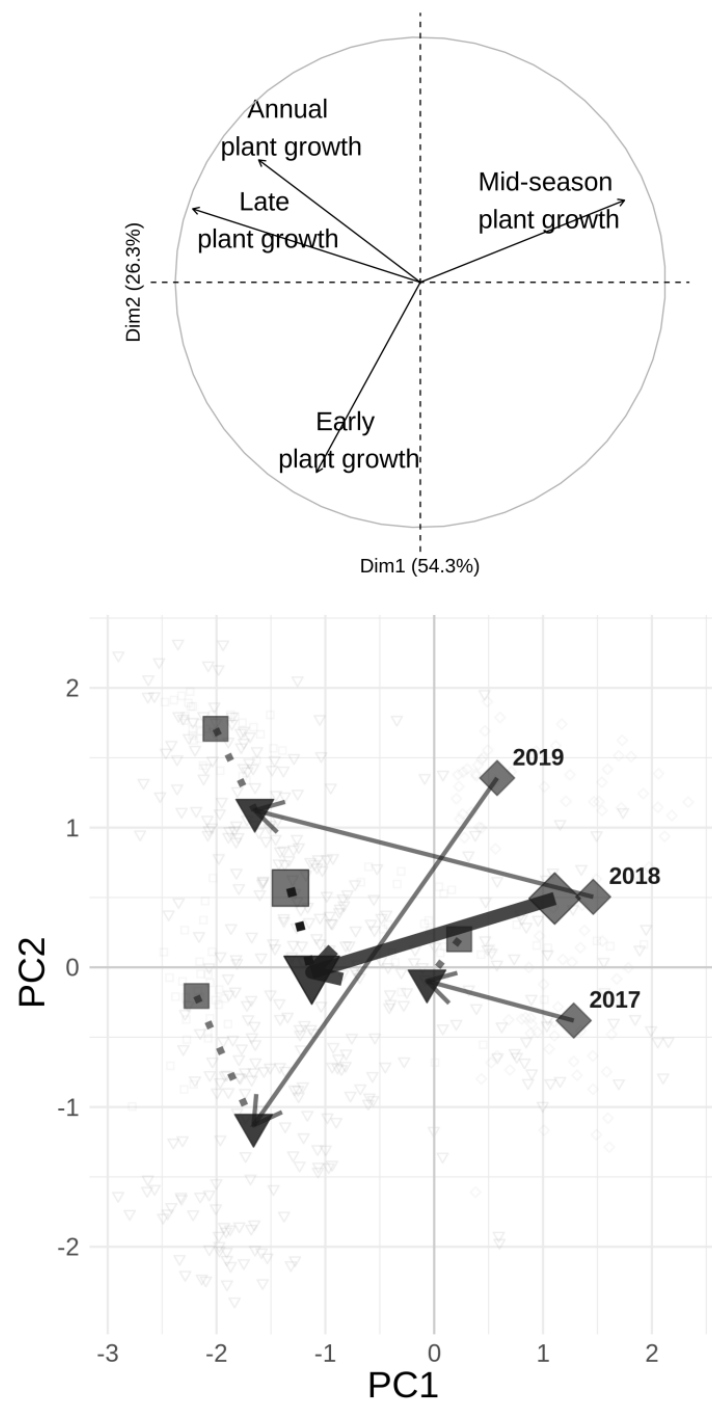

B) Forbs
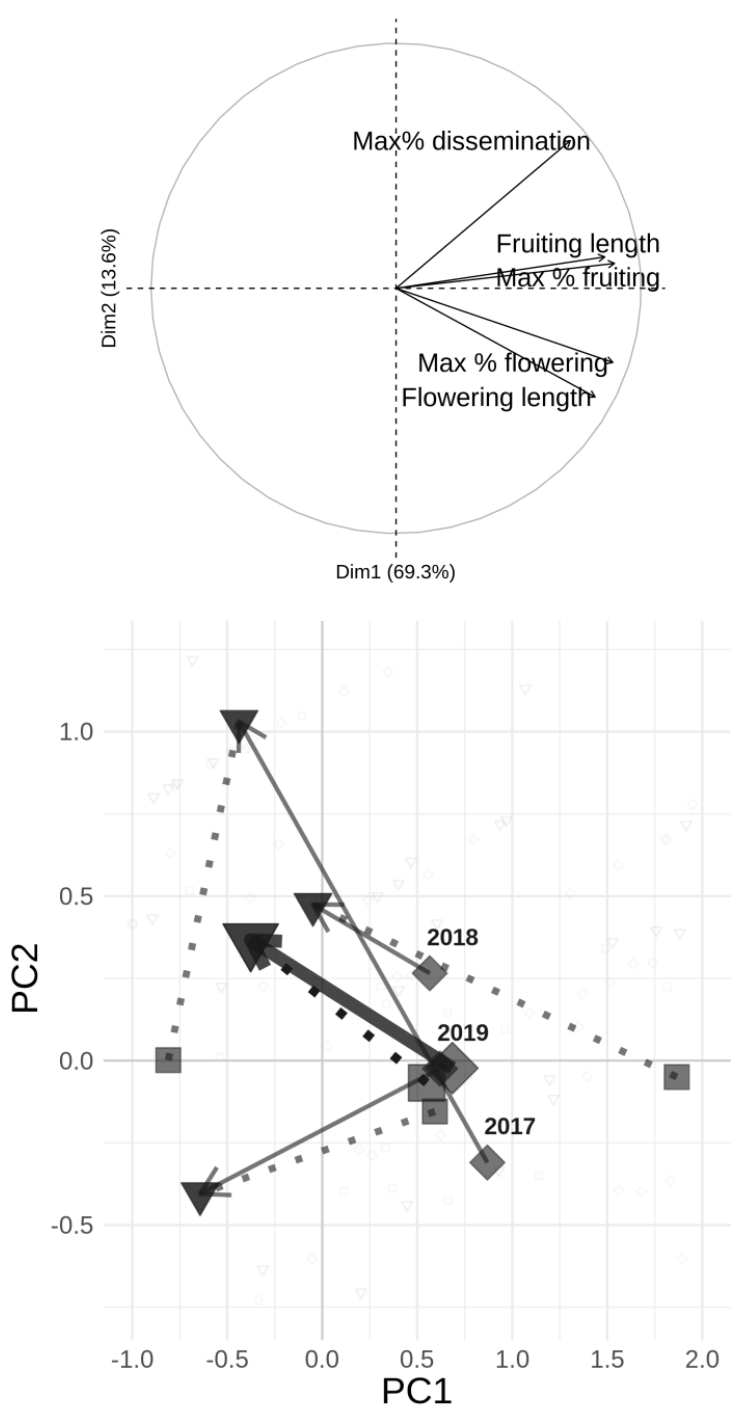

C) Graminoids
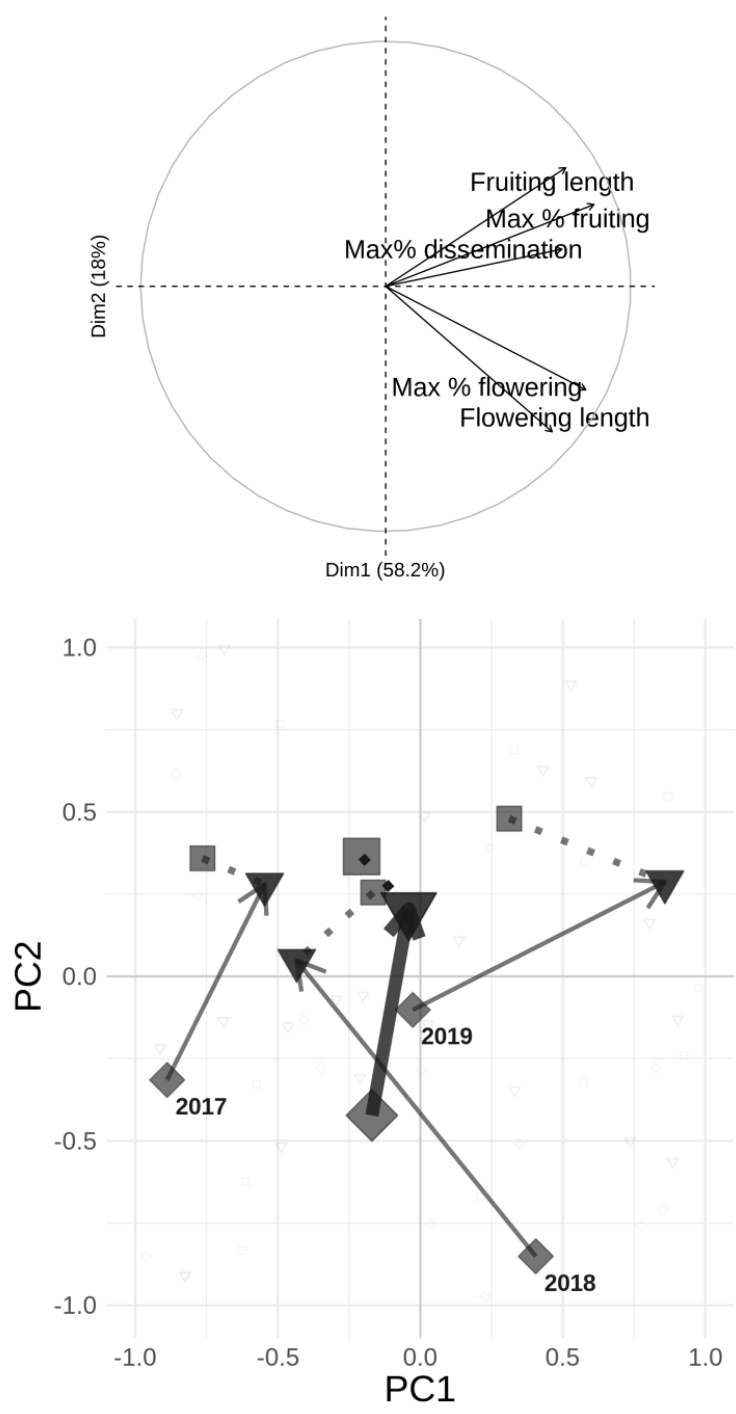

Warming effect

AlpineControl

SubalpineControl

AlpineWarmed 
Figure S7: Differences in performance related phenological indicators (plotted in a two-dimensional PCA space) between the three treatments (AlpineWarmed, AlpineControl and SubalpineControl) at the community (A) and the species level (forbs (B) and

gramminoids $(C)$ ). Straight arrows highlight warming effect (AlpineWarmed-AlpineControl) and dotted lines the acclimation lag after warming (SubalpineControl-AlpineWarmed). Thicker lines indicate the overall response for three years. Thinner lines indicate annual response. (diamond: AlpineControl, square: SubalpineControl, inverse triangle: AlpineWarmed). For further analyses, the first two $P C$ s were selected from $(A)$ and only the first PC from (B) and (C). 


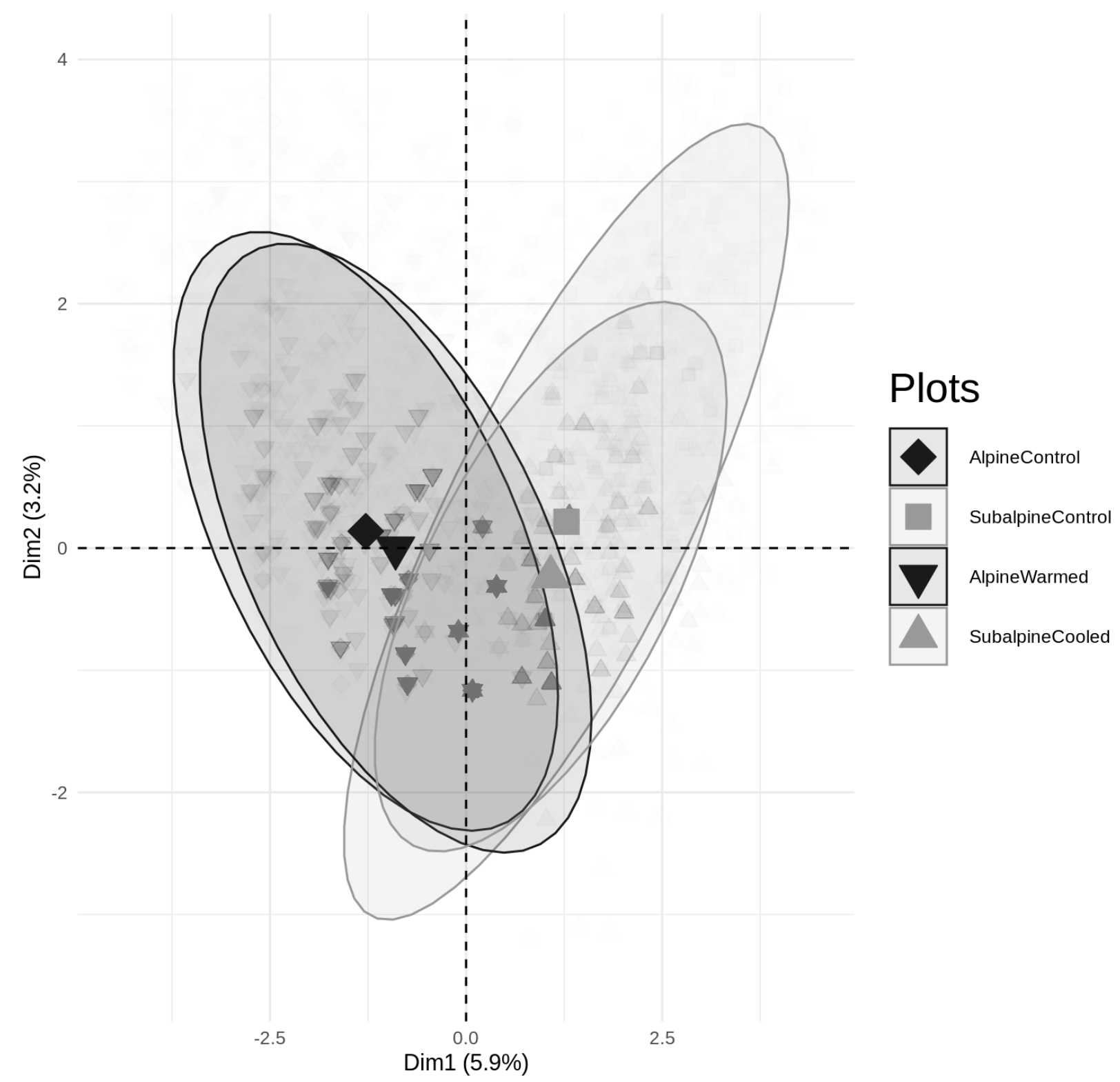

Figure S8: Principal component analysis (PCA) of community composition from abundance data collected in 2018 of dominant species in both alpine and subalpine sites. (diamond: AlpineControl, square: SubalpineControl, inverse triangle: AlpineWarmed, triangle: SubalpineCooled). 


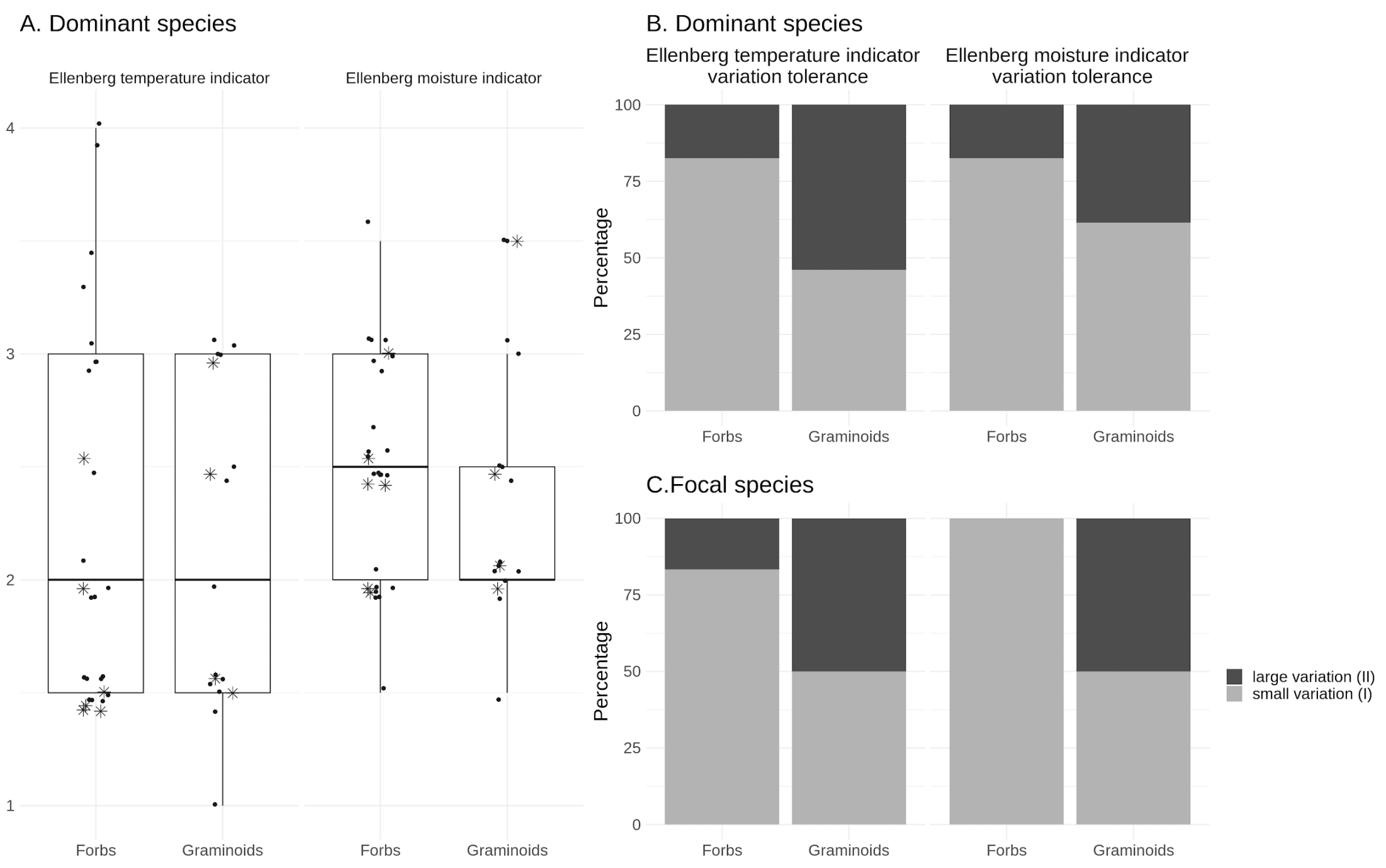

Figure S9: (A) Ellenberg temperature and moisture indicator values of dominant species in alpine and subalpine site. The values of the focal species are shown in star. Percentages of number of species that can tolerate small or large variation in their Ellenberg temperature and moisture indicator values $(B)$ for dominant species in both sites and $(C)$ for focal species in the study. 


\section{Appendix S10: Cascading acclimation lag: From phenological indicators to flower visiting insects}

Grassland phenology can have strong impacts on pollination services. As we found that warmed alpine forbs' communities flowered less often, for shorter time periods and tendentially earlier than subalpine forbs' communities (Figure 2), we asked whether this had any cascading effect on flower visiting behavior of insects.

To answer this question we observed insects visiting flowers in the AlpineWarmed, AlpineControl and SubalpineControl plots between June and September in 2019. Observations were limited to conditions favourable for insect visits, i.e. between 10:00 and 13:00 and only if it was warm enough, not too cloudy (either $>13^{\circ} \mathrm{C}$ if less than half of the sky was covered with clouds or $>15^{\circ} \mathrm{C}$ otherwise) and not too windy (maximum $29.5 \mathrm{~km} / \mathrm{h}$ ). Each week (and twice at the peak of growing season) we spent 10 minutes at each of 8 randomly chosen replicates of each treatment to observe flower visits (summing up to a total of 1400 observation minutes). We counted all insects that visited a flower within a $1 \mathrm{~m}^{2}$ focal area during this standardized time period. We only identified main insect groups following the guidelines of the public science UK PoMS, Pollinator Monitoring Scheme (https://www.ceh.ac.uk/our-science/projects/pollinator-monitoring) because the observations were done by non-expert interns.

Pollinator visits per minute were generally quite low (AlpineControl: 0.34, AlpineWarmed: 0.04, SubalpineControl:0.2, SubalpineCooled: 0.32). We found strong site-specific effects on pollinator communities, with more flies and small insects $(<3 \mathrm{~mm})$ in AlpineControl plots and more Coleoptera and Hymenoptera species in SubalpineControl plots. Overall, AlpineControl plots tended to attract slightly more visits than SubalpineControl plots. Due to these site specific differences, we focus on acclimation lags comparing AlpineWarmed and SubalpineControl plots that are at the same site and thus available to the same pollinator community. Our main results show that the flowers in AlpineWarmed plots were visited by a significantly less diverse group of insects and also had a tendency to be overall less visited than the SubalpineControl plots (Figure S10).

As AlpineWarmed and Subalpine Control plots are at the same location (randomly placed at the site) and have been observed at the same moment, differences in flower visiting insects are clearly due to plot-level vegetation differences. We conclude that reduced flower numbers, shorter flowering periods and premature flowering are among the main drivers of impaired flower visiting of insects creating a cascading acclimation lag from plant phenology to insect pollination. 


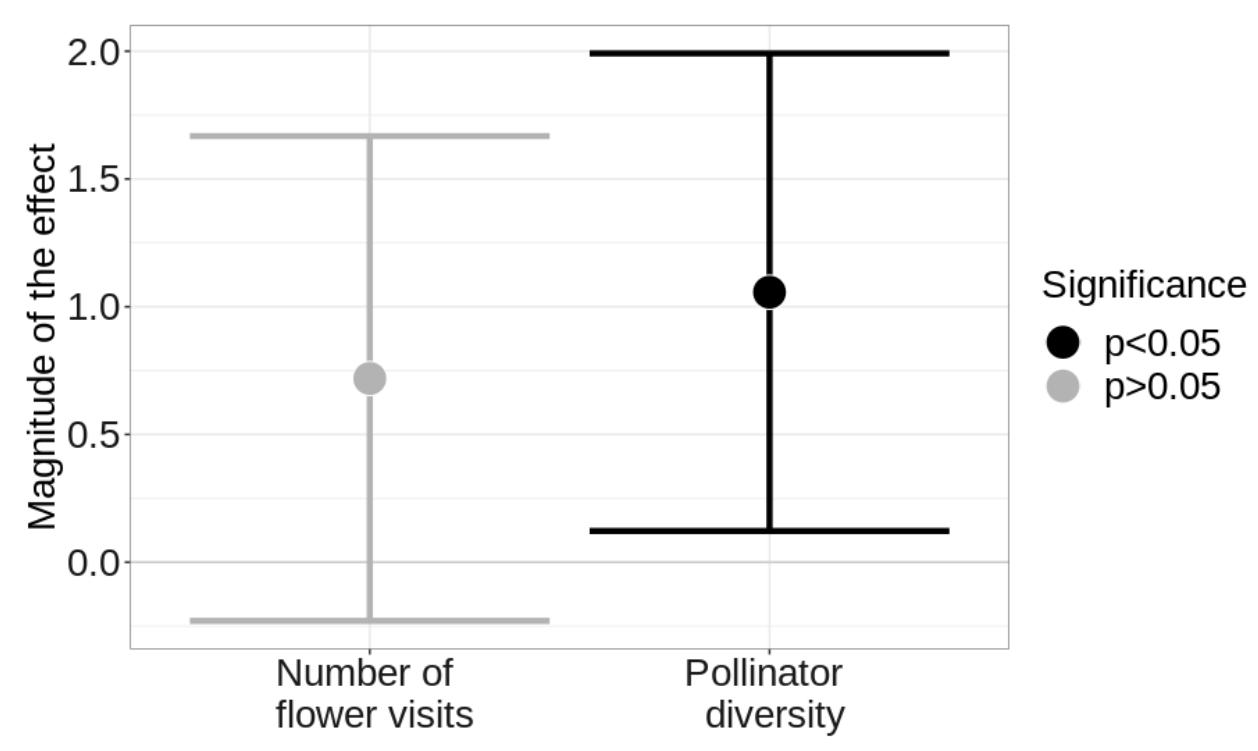

Figure S.10: Acclimation lags after warming (Standardized effect sizes of the difference between SubalpineControl and AlpineWarmed). Significant results are shown in black. Error bars represent $95 \%$ confidence intervals. 

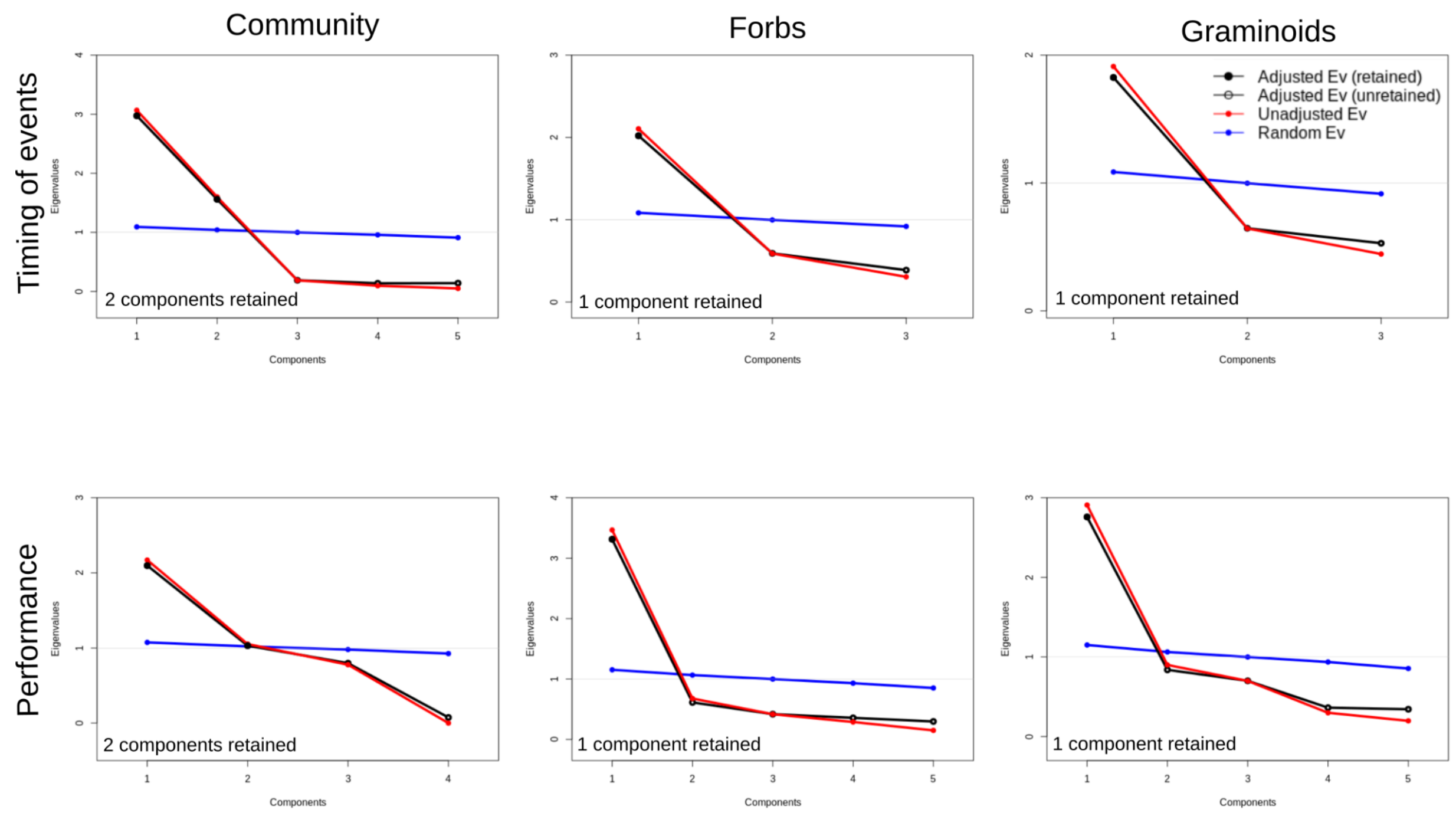

Figure S12: Results from Horn's parallel analysis to select the number of principal components from each PCA (Appendix Figure S4-7). 


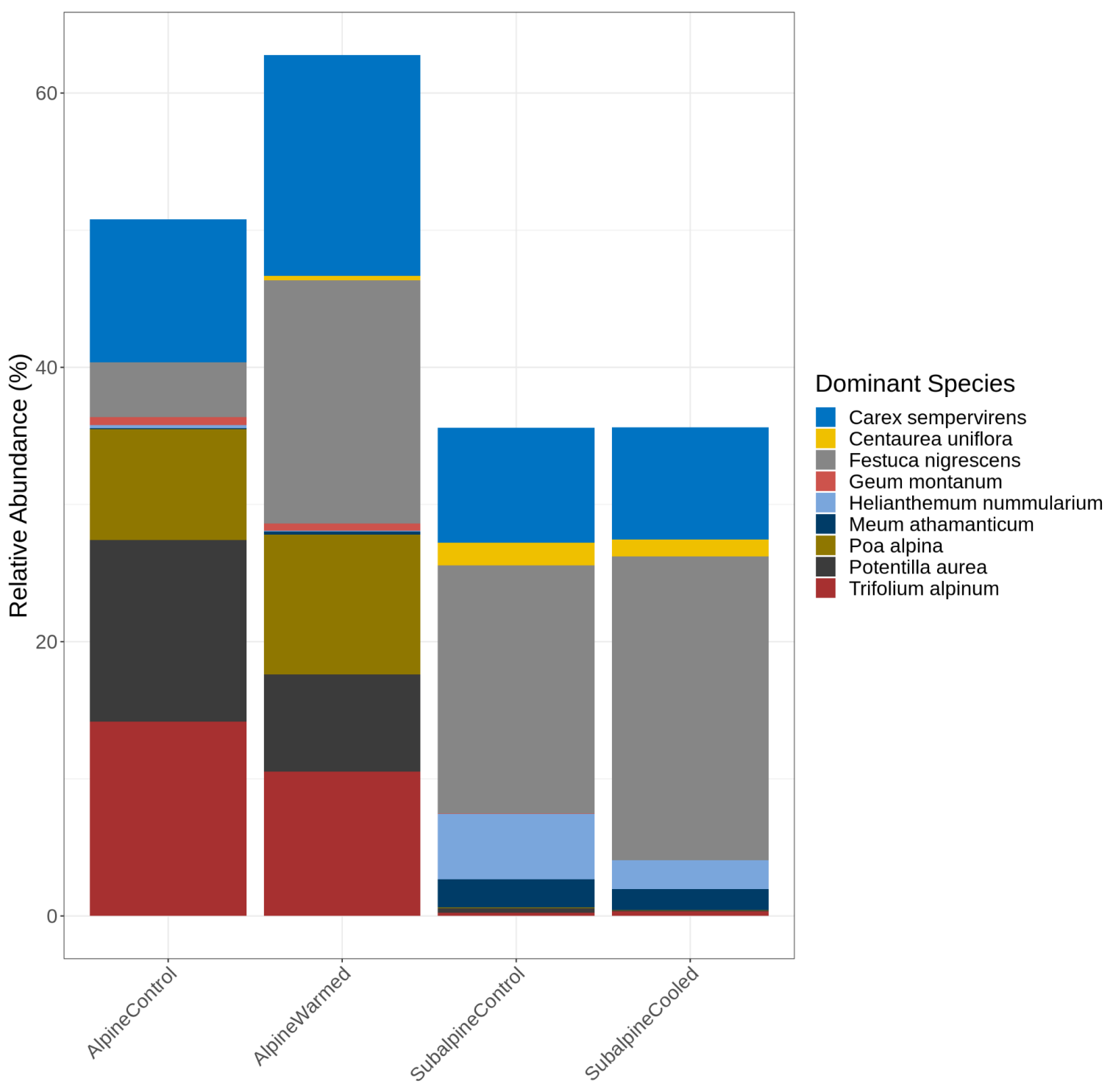

Figure S13: Relative abundances (\%) of dominant species in the different experimental plots. These are calculated from a separate dataset of species abundances collected in 2018, i.e. two years after the transplantation. 